OPEN ACCESS

Edited by:

Cecilia Hillard,

Medical College of Wisconsin,

United States

Reviewed by:

Julian Romero,

Universidad Francisco de Vitoria,

Spain

Natasha L. Grimsey,

The University of Auckland,

New Zealand

${ }^{*}$ Correspondence:

Alexander P. Young

alex.young@dal.ca

Eileen M. Denovan-Wright

emdenova@dal.ca

Specialty section:

This article was submitted to

Experimental Pharmacology and Drug

Discovery,

a section of the journal

Frontiers in Pharmacology

Received: 31 October 2021 Accepted: 24 December 2021

Published: 04 February 2022

Citation:

Young $A P$ and Denovan-Wright EM (2022) The Dynamic Role of Microglia and the Endocannabinoid System in Neuroinflammation.

Front. Pharmacol. 12:806417. doi: 10.3389/fphar.2021.806417

\section{The Dynamic Role of Microglia and the Endocannabinoid System in Neuroinflammation}

\author{
Alexander P. Young * and Eileen M. Denovan-Wright * \\ Department of Pharmacology, Dalhousie University, Halifax, NS, Canada
}

Microglia, the resident immune cells of the brain, can take on a range of pro- or antiinflammatory phenotypes to maintain homeostasis. However, the sustained activation of pro-inflammatory microglia can lead to a state of chronic neuroinflammation characterized by high concentrations of neurotoxic soluble factors throughout the brain. In healthy brains, the inflammatory processes cease and microglia transition to an anti-inflammatory phenotype, but failure to halt the pro-inflammatory processes is a characteristic of many neurological disorders. The endocannabinoid system has been identified as a promising therapeutic target for chronic neuroinflammation as there is evidence that synthetic and endogenously produced cannabinoids temper the pro-inflammatory response of microglia and may encourage a switch to an anti-inflammatory phenotype. Activation of cannabinoid type $2\left(\mathrm{CB}_{2}\right)$ receptors has been proposed as the mechanism of action responsible for these effects. The abundance of components of the endocannabinoid system in microglia also change dynamically in response to several brain pathologies. This can impact the ability of microglia to synthesize and degrade endocannabinoids or react to endogenous and exogenous cannabinoids. Cannabinoid receptors also participate in the formation of receptor heteromers which influences their function specifically in cells that express both receptors, such as microglia. This creates opportunities for drug-drug interactions between $\mathrm{CB}_{2}$ receptor-targeted therapies and other classes of drugs. In this article, we review the roles of pro- and anti-inflammatory microglia in the development and resolution of neuroinflammation. We also discuss the fluctuations observed in the components of the endocannabinoid in microglia and examine the potential of $\mathrm{CB}_{2}$ receptors as a therapeutic target in this context.

Keywords: neuroinflammation, endocannabinoid system, $\mathrm{CB}_{2}$ receptor, microglia, MAPK signaling, heteromer, GPCR (G protein coupled receptor)

\section{INTRODUCTION}

Neuroinflammation is characterized by sustained activation of microglia which release toxic cytokines that cause widespread damage to the brain. Microglia are recognized as the resident immune cells of the brain and have been identified as active propagators of neuroinflammation throughout the progression of several neurodegenerative diseases (Perry et al., 2010). At rest, microglia secrete neurotrophins and clear debris to support the maintenance of normal brain function (Cherry et al., 2014a). These unreactive microglia survey their environment using scavenger receptors to sense disruptions to local homeostasis (Nimmerjahn et al., 2005). Microglia detect 
soluble factors released by neurons, astrocytes, other microglia, and infiltrating peripheral immune cells and may transition toward either an activated M1 (pro-inflammatory) or M2 (anti-inflammatory) phenotype to maintain homeostasis (Chhor et al., 2013). M1 microglia mediate host defense and are characterized by regulated phagocytic activity and the release of pro-inflammatory cytokines such as interleukin (IL)- $1 \beta$ and tumour necrosis factor alpha (TNFa) (Chhor et al., 2013). If these cytokines reach sufficient concentrations, they will trigger neuronal signaling cascades that cause cell impairment or necrosis (Neumann et al., 2002; Bachiller et al., 2018). In a healthy brain, the inflammatory process will halt before this occurs and M1 microglia will transition toward a more antiinflammatory M2 phenotype to release anti-inflammatory cytokines, clear debris from dead cells, promote angiogenesis, and deposit extracellular matrix (Varin and Gordon, 2009; Cherry et al., 2014b). However, failure to halt the inflammatory process and engage M2 microglia is a common characteristic of several neurological disorders (Cherry et al., 2014b).

Microglia possess the necessary components required to synthesize, degrade, and respond to extracellular endocannabinoids (Stella, 2009; Stella, 2010). The endocannabinoid system comprises the cannabinoid type 1 $\left(\mathrm{CB}_{1}\right)$ and type $2\left(\mathrm{CB}_{2}\right)$ receptors, the endogenous ligands anandamide (AEA) and 2-arachidonylglycerol (2-AG), as well as the enzymes that regulate their production ( $\mathrm{Lu}$ and Mackie, 2016). Anandamide was the first identified endocannabinoid which is known to bind $\mathrm{CB}_{1}$ receptors as well as $\mathrm{CB}_{2}$ receptors with relatively low affinity (Devane et al., 1992; Felder et al., 1993). AEA is synthesized by the enzyme $\mathrm{N}$-acyl phosphatidylethanolamine-specific phospholipase D (NAPEPLD) and degraded by fatty acid amide hydrolase (FAAH). The second identified endocannabinoid was 2arachidonoylglycerol (2-AG) which also activates both $\mathrm{CB}_{1}$ and $\mathrm{CB}_{2}$ receptors (Mechoulam et al., 1995; Sugiura et al., 1995; Stella et al., 1997). In human serum, 2-AG is up to 100fold more abundant than AEA (Hillard et al., 2012). 2-AG is synthesized by diacylglycerol lipase (DAGL) and degraded primarily by monoacylglycerol lipase (MAGL) as well as alpha/beta-hydrolase domain (ABHD) containing enzymes such as ABHD6 and ABHD12 (Di Marzo et al., 1994; Cravatt et al., 2001). Although both endocannabinoids have effects on analgesia, AEA has greater effects on depression and anxiety whereas 2-AG appears to contribute more to the effects on movement and temperature regulation (Kathuria et al., 2003; Gobbi et al., 2005; Long et al., 2009). When both endocannabinoids are elevated through dual blockade of FAAH and MAGL, the effects mimic that of $\Delta 9$ tetrahydrocannabinol $\left(\Delta^{9}\right.$-THC) from Cannabis (Long et al., 2009; Alger and Kim, 2011).

Cannabinoid receptors are $G$ protein-coupled receptors (GPCRs) that typically couple to $\mathrm{Ga}_{\mathrm{i}}$ but have been observed to couple to $\mathrm{Ga}_{\mathrm{o}}$ and $\mathrm{Ga}$ s under some circumstances (Glass and Felder, 1997; Howlett et al., 2002; Saroz et al., 2019). $\mathrm{CB}_{1}$ receptors are abundant in central neurons and inhibit transmitter release upon activation (Howlett et al., 2002). $\mathrm{CB}_{2}$ receptors display a distinct pharmacological profile and are more abundant in peripheral immune cells as well as in microglia (Galiègue et al., 1995; Howlett et al., 2002; Stella, 2009). $\mathrm{CB}_{1}$ receptors generally exert the psychoactive effects of $\Delta^{9}$-THC, whereas $\mathrm{CB}_{2}$ receptors primarily mediate the immunosuppressive and anti-inflammatory effects of select cannabinoid molecules (Bouaboula et al., 1993; Lynn and Herkenham, 1994; Galiègue et al., 1995; Marsicano and Lutz, 1999). Pro-inflammatory and anti-inflammatory microglial phenotypes exhibit changes in the concentration of endocannabinoids as well as differences in the enzymatic machinery to synthesize and metabolize them (Maresz et al., 2005; Mecha et al., 2015). Furthermore, the quantities of the cannabinoid receptors have been observed to fluctuate widely in response to different pro- and anti-inflammatory stimuli. Current data that describe which components of the endocannabinoid system are upregulated or downregulated in each phenotype is useful to understand that the endocannabinoid system is a moving target in the context of neuroinflammation.

Neuroinflammation is a hallmark of aging as well as neurodegenerative diseases including Alzheimer's disease (AD), Parkinson's disease (PD), and Huntington's disease (HD) (Guzman-Martinez et al., 2019). Each of these neurodegenerative diseases are characterized by overactivation of microglia and have a neuroinflammatory component which could be a common target for therapeutics. The endocannabinoid system has been identified as a promising source of targets for the treatment of such chronic neuroinflammation (Pacher et al., 2006; Ashton and Glass, 2007; Saito et al., 2012). However, the molecular mechanisms that underlie the success of these treatments have not been clearly defined (Tanaka et al., 2020). Cannabinoids appear to dampen the pro-inflammatory microglial phenotype via multiple signaling pathways to regulate the transition from a resting to an anti-inflammatory microglial phenotype. To add an additional layer of complexity, cannabinoid receptors have recently been found to form oligomeric receptor complexes which respond differently to cannabinoids relative to the individual receptors; this may allow for unanticipated drug-drug interactions among $\mathrm{CB}_{2}$ receptor agonists and other cannabinoids or other classes of drugs that target microglia. In this review, we discuss the roles of pro- and anti-inflammatory microglia in the development and resolution of neuroinflammation. We also discuss the fluctuations observed in the components of the endocannabinoid in microglia and examine the potential of $\mathrm{CB}_{2}$ receptors as a therapeutic target in this context.

\section{MICROGLIAL PHENOTYPES AND THE ENDOCANNABINOID SYSTEM}

The microglial endocannabinoid system changes substantially among different phenotypes (Figure 1). At rest, microglia engage in several tasks including surveillance of the brain parenchyma and the maintenance of synapse function, and the abundance of $\mathrm{CB}_{1}$ and $\mathrm{CB}_{2}$ receptors is expected to be relatively low (Nimmerjahn et al., 2005; Stella, 2010). Early reports indicated that $\mathrm{CB}_{1}$ and $\mathrm{CB}_{2}$ receptor mRNA was undetectable within 


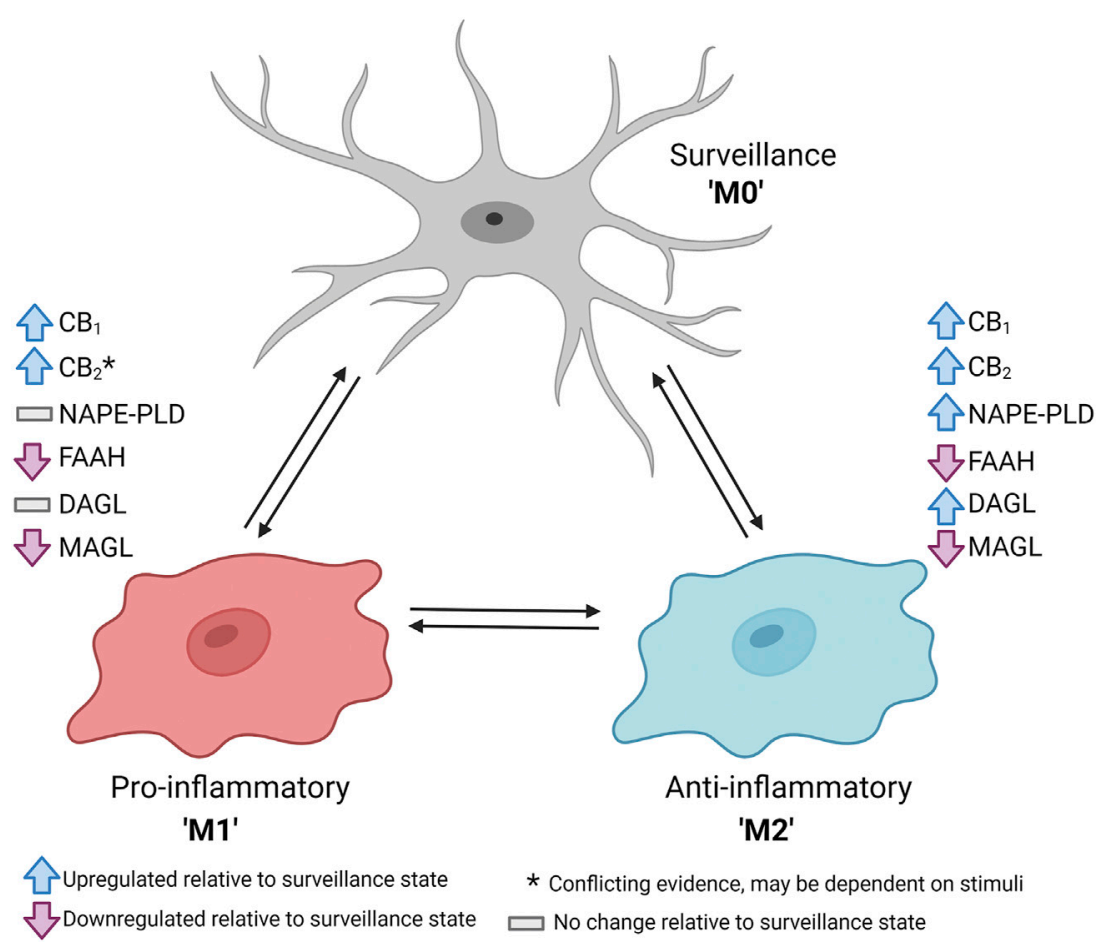

FIGURE 1 | Schematic summary of changes in the components of the endocannabinoid system upon dynamic shift from unreactive or surveillance (M0) phenotype to a pro-inflammatory (M1) or anti-inflammatory (M2) phenotype. Data derived primarily from Maresz et al. (2005), Mecha et al. (2015), and Navarro et al. (2018). Figure created with BioRender.

healthy brain tissue lysate or in isolated resting microglia (Munro et al., 1993; Galiègue et al., 1995; Schatz et al., 1997; Griffin et al., 1999; McCoy et al., 1999; Sugiura et al., 2000; Carlisle et al., 2002). However, other reports have indicated that resting microglia expressed both cannabinoid receptors, although perhaps only in trace amounts (Núñez et al., 2004; Navarro et al., 2018). Unreactive glia have been observed to release both AEA and 2-AG at a ratio of roughly 1:100 (Mecha et al., 2015; Araujo et al., 2019). If endocannabinoids released by resting microglia interacted with local synapses, $\mathrm{CB}_{1}$ receptors could be activated to inhibit transmitter release from the pre-synaptic neurons via modulation of intracellular calcium, cyclic AMP, and inwardly rectifying potassium currents (Howlett et al., 2002). However, it is still uncertain whether endocannabinoids released specifically by microglia directly influence the activity of local synapses.

Under conditions of neuroinflammation, microglia engage in a pro-inflammatory M1 phenotype which includes several changes to their endocannabinoid function. Maresz et al. (2005) initially observed that $\mathrm{CB}_{2}$ receptor mRNA was upregulated by 100 -fold in the central nervous system (CNS) of mice with experimental autoimmune encephalitis. The pattern was consistent in primary mouse microglia treated with interferon- $\gamma$ (IFN $\gamma)$. These findings were replicated in immortalized N9 microglia as stimulation with IFN $\gamma$ and lipopolysaccharide (LPS) caused a 12-fold increase in $\mathrm{CB}_{2}$ receptor mRNA (Navarro et al., 2018). Conversely, primary rat microglia stimulated with LPS for $6 \mathrm{~h}$ exhibited a global downregulation of the components of the endocannabinoid system, including mRNA for $\mathrm{CB}_{1}$ and $\mathrm{CB}_{2}$ receptors, NAPEPLD and FAAH, as well as DAGLa, DAGL $\beta$, and MAGL (Mecha et al., 2015). After 24 h, FAAH and MAGL remained depressed, but the other components returned to baseline which may be indicative of a compensatory mechanism to favour synthesis of endocannabinoids following pro-inflammatory insult. Taken together, it appears that the regulation of $\mathrm{CB}_{2}$ receptors and other components of the endocannabinoid system in microglia under pro-inflammatory conditions may depend on the type of stimuli or the length of time exposed to such conditions. Interestingly, recent RNA sequencing data revealed that microglia isolated from $\mathrm{CB}_{2}$ receptor knockout mice failed to transition to an M1 phenotype in response to IFN $\gamma$ and LPS (Reusch et al., 2021). This is indicative of potential crosstalk between $\mathrm{CB}_{2}$ receptor-mediated signaling and the effects of tolllike or IFN receptors. Thus, constitutive $\mathrm{CB}_{2}$ receptor activation may facilitate the initial transition to a pro-inflammatory phenotype.

To assist with the resolution of neuroinflammation, microglia take on an anti-inflammatory M2 phenotype which includes unique changes to microglial endocannabinoid function (Tanaka et al., 2020). Mecha et al. (2015) determined that rat microglia treated with IL- 4 and IL-13 for $6 \mathrm{~h}$ had an enhanced abundance of mRNA for $\mathrm{CB}_{2}$ receptors and DAGLa. After $24 \mathrm{~h}$, mRNA for $\mathrm{CB}_{1}$ receptors and NAPE-PLD became elevated, and 
DAGLa had returned to baseline. These cells also exhibited reduced mRNA for FAAH and MAGL in both the 6- and 24$\mathrm{h}$ treatment groups. Furthermore, these M2 microglia also released more AEA and 2-AG (Mecha et al., 2015). This indicates that microglia in an M2 phenotype promote the synthesis of both endocannabinoids and have a lower quantity of degradative enzymes relative to the resting or M1 phenotypes. The same authors also determined that treatment of microglia with endocannabinoids in vitro caused an upregulation of both $\mathrm{CB}_{1}$ and $\mathrm{CB}_{2}$ receptor mRNA abundance (Mecha et al., 2015). Activation of either $\mathrm{CB}_{1}$ or $\mathrm{CB}_{2}$ receptors by endocannabinoids has also been demonstrated to induce a shift toward an M2 phenotype in microglia, with upregulation of mRNA and protein for anti-inflammatory markers such as Arg-1 and SOCS-3 (Correa et al., 2010; Correa et al., 2011; Mecha et al., 2015). Taken together, the current evidence suggests that endocannabinoids promote microglia to shift toward an M2 phenotype which contributes to a feed-forward loop to upregulate cannabinoid receptor expression and release more endocannabinoids. Finally, microglia treated with IL-4 and IL-13 exhibited a substantial increase in Arg-1 mRNA and protein, but the effect was fully blocked by selective antagonists for either $\mathrm{CB}_{1}$ receptors (AM251) or $\mathrm{CB}_{2}$ receptors (AM630) (Mecha et al., 2015). Thus, constitutive activity of both $\mathrm{CB}_{1}$ and $\mathrm{CB}_{2}$ receptors may be required to enable the transition from an unreactive to an M2 phenotype.

\section{MICROGLIAL PHENOTYPES AND NEUROINFLAMMATION WITH DISEASE AND AGING}

Changes in microglial phenotype have been observed in neurodegenerative diseases such as $\mathrm{AD}, \mathrm{PD}$, and $\mathrm{HD}$ as well as with normal aging. Each of these states also exhibit unique changes to the endocannabinoid system which includes fluctuations in global AEA and 2-AG concentrations as well as changes in $\mathrm{CB}_{1}$ and $\mathrm{CB}_{2}$ receptor abundance (Supplementary Table S1). Although the components of the endocannabinoid system vary in microglia among pathologies, the cannabinoid receptors have shown promise as therapeutic targets for the treatment of neuroinflammation and neurodegeneration.

\section{Alzheimer's Disease}

$\mathrm{AD}$ is characterized by the aggregation of amyloid-beta $(\mathrm{A} \beta)$ that form extracellular plaques and accumulation of intracellular tau protein that form neurofibrillary tangles (Bloom, 2014). The buildup of cellular plaques and tangles results in the death of affected neurons with a subsequent decline in cognitive function (Selkoe and Hardy, 2016). The cause of AD was initially ascribed to insufficient clearance of $A \beta$ aggregates and hyperphosphorylated tau protein (Murphy and LeVine, 2010). In $\mathrm{AD}$ mice, microglia are observed near $\mathrm{A} \beta$ plaques at five-fold the normal density, the purpose of which has been proposed to be clearance of A $\beta$ by phagocytosis (Frautschy et al., 1998; D'Andrea et al., 2004). However, current evidence indicates that microglia do not influence the size or number of $A \beta$ plaques in the late stages of AD (Spangenberg et al., 2016). More recent data has demonstrated that ablation of microglia in $\mathrm{AD}$ mice using a colony-stimulating factor 1 (CSF1) antagonist prevented the formation of these plaques which indicates that microglia may not be responsible for $A \beta$ clearance but may in fact contribute to the initial deposition of $A \beta$ plaques (Spangenberg et al., 2019). Furthermore, the accumulation of activated non-plaque associated microglia may lead to a sustained localized release of proinflammatory cytokines including IL-1 $\beta$, IL-6, NO, and TNFa which are also neurotoxic (Benzing et al., 1999; Abbas et al., 2002; Wang et al., 2015). The increased concentration of these cytokines could exacerbate the accumulation of $\mathrm{A} \beta$ and produce further damage to the brain (Hickman et al., 2008). The severity of $\mathrm{AD}$ dementia has shown to be positively correlated with markers of pro-inflammatory microglial activation (Nordengen et al., 2019). Although originally thought of as a secondary effect of plaque formation, neuroinflammation is now understood to contribute equally to $\mathrm{AD}$ progression compared to the canonical protein aggregates (Zhang et al., 2013; Heneka et al., 2015).

Mouse models of AD have consistently demonstrated specific changes in the endocannabinoid system, including upregulation of $\mathrm{CB}_{2}$ receptors and dysregulation of 2-AG metabolism (Mulder et al., 2011; Cristino et al., 2020). Enhanced $\mathrm{CB}_{2}$ receptor-like immunoreactivity was found localized within plaque-associated microglia in human AD tissue (Benito et al., 2003). The same pattern of elevated $\mathrm{CB}_{2}$ receptor-like immunoreactivity in human AD brains was later reported (Halleskog et al., 2011). Western blots from human $\mathrm{AD}$ brain lysate later corroborated that $\mathrm{CB}_{2}$ receptor protein was elevated in the frontal cortex (Solas et al., 2013). Rats that received intracerebral injection of $30 \mathrm{ng}$ of $\mathrm{A} \beta$ exhibited 2.7-fold increased $\mathrm{CB}_{2}$ receptor mRNA abundance (Esposito et al., 2007). Aso et al. (2013) identified that the APP/PS1 mouse model of $\mathrm{AD}$ exhibited 1.4-fold increased $\mathrm{CB}_{2}$ receptor mRNA abundance. Examinations of human $\mathrm{AD}$ brains have shown no change in total protein for NAPE-PLD or FAAH (Mulder et al., 2011), although FAAH activity may be selectively upregulated in the plaque-associated glia (Benito et al., 2003). Conversely, substantial changes have been observed in the metabolic enzymes for 2-AG (Mulder et al., 2011). Tissue from human $\mathrm{AD}$ brains revealed a positive correlation between disease stage and upregulation of DAGL and MAGL, with no alteration in ABHD6 (Mulder et al., 2011). Isolated membrane and cytosolic fractions from this tissue also exhibited a faster rate of 2-AG degradation compared to control tissue. Concentrations of AEA have been positively correlated with cognitive function in $\mathrm{AD}$ patients but negatively correlated with abundance of $A \beta_{42}$ which indicates that $\mathrm{AD}$ is also associated with dysregulated AEA production (Jung et al., 2012). Ultimately, brains afflicted with AD exhibit reduced endocannabinoid signaling which is likely caused by enhanced degradation of endocannabinoids without a compensatory increase in the synthetic enzymes.

$\mathrm{CB}_{2}$ receptor activation has demonstrated potential benefits in several models of $\mathrm{AD}$ to dampen neuroinflammation and improve cognition (Martín-Moreno et al., 2012; Cassano et al., 2017; Li et al., 2019). The nonselective cannabinoid agonist, WIN55212-2, dampened the inflammatory response in rats 
that received hippocampal injection of $A \beta$ (Fakhfouri et al., 2012). APP/PS1 mice administered a selective $\mathrm{CB}_{2}$ receptor agonist, JWH-133, exhibited a partial rescue of cognitive deficits as determined by an active avoidance test and a $\mathrm{V}$-maze memory test (Aso et al., 2013). This improvement in cognitive performance was accompanied by a reduction in the proinflammatory markers IL-1 $\beta$, IL-6, and TNFa. However, the drug was only effective when administered at the presymptomatic stage. Furthermore, JWH-133 had no effect on the quantity of $A \beta$ in the brain (Aso et al., 2013). Mice that received JWH-133 also exhibited greater numbers of microglia that expressed elevated levels of IL-6 and IL-10 which was indicative of immunoregulatory activity (Aso et al., 2013; Chhor et al., 2013). Activation of microglial $\mathrm{CB}_{2}$ receptors has also been shown to stimulate phagocytosis of $\mathrm{A} \beta$ in vivo and in vitro (Tolón et al., 2009; Aso et al., 2016). Thus, activation of microglial $\mathrm{CB}_{2}$ receptors appears to serve a dual purpose to enhance phagocytosis of $A \beta$ plaques and dampen neuroinflammation.

\section{Parkinson's Disease}

$\mathrm{PD}$ is characterized by motor dysfunction due to damage to dopaminergic neurons of the nigrostriatal pathway. Activated M1 microglia have been determined to be closely associated with neuron damage in human PD brains (McGeer et al., 1988). Imamura et al. (2003) found that the abundance of CD54/ $\mathrm{CD}_{11 \mathrm{a}^{+}}$microglia was correlated with progressive neurodegeneration in the substantia nigra. Increased proportions of activated microglia were also located in the caudate nucleus, hippocampus, transentorhinal cortex, cingulate cortex, and temporal cortex compared to the healthy control subjects. These activated microglia were also positive for TNF $\alpha$ and IL-6 which was indicative of an M1 phenotype. Subsequent studies have supported the elevated presence of M1 microglia in PD brains (Ouchi et al., 2005; Gerhard et al., 2006). However, quantities of activated microglia were not necessarily correlated with clinical severity (Gerhard et al., 2006). Dopaminergic neurons of the midbrain have been shown to be especially sensitive to the toxic effects of microglial cytokines including TNFa (McGuire et al., 2001). Thus, this population of neurons is highly susceptible to severe damage triggered by neuroinflammation that is characterized by the perpetuating cycle of neuron death with subsequent reactive microglial activation and cytokine release.

There are conflicting reports with respect to fluctuating levels of $\mathrm{CB}_{1}$ and $\mathrm{CB}_{2}$ receptors in $\mathrm{PD}$. Elevated $\mathrm{CB}_{1}$ receptor mRNA has been observed in the caudate putamen but not the substantia nigra of human PD brains (Navarrete et al., 2018). In non-human primates subjected to 1-methyl-4-phenyl-1,2,3,6tetrahydropyridine (MPTP)-induced neurotoxicity, $\mathrm{CB}_{1}$ receptor mRNA was elevated in the globus pallidus and subthalamic nucleus in response to levodopa-induced dyskinesia (Rojo-Bustamante et al., 2018). $\mathrm{CB}_{2}$ receptor mRNA abundance was also elevated in the substantia nigra but diminished in the caudate putamen in human and mouse tissues (Gómez-Gálvez et al., 2016; Navarrete et al., 2018). Immunofluorescence labeling of human PD brains supported that the elevation in $\mathrm{CB}_{2}$ receptors was primarily in activated microglia within the substantia nigra pars compacta (GómezGálvez et al., 2016). In the MPTP-induced neurotoxicity model of PD, Price et al. (2009) identified elevated levels of $\mathrm{CB}_{2}$ receptor protein in the ventral midbrain via western blot and immunofluorescence. This labeling colocalized with $\mathrm{CD} 1 \mathrm{~b} /$ $\mathrm{CD} 18^{+}$cells which indicated that the $\mathrm{CB}_{2}$ receptors were indeed expressed in activated microglia. In the reserpineinduced animal model of $\mathrm{PD}$, a substantial increase in 2-AG and AEA was observed in the globus pallidus (Di Marzo et al., 2000). A similar increase in 2-AG was also found in the mouse ventral midbrain using an MPTP-treated mouse model (Mounsey et al., 2015). Elevated AEA was also found in the basal ganglia of rats lesioned with 6-hydroxy dopamine (6-OHDA) (Maccarrone et al., 2003). This was accompanied by reduced FAAH activity in the striatum. Thus, endocannabinoid production appears to be elevated in PD, perhaps as a compensatory mechanism to dampen the associated neuroinflammation.

Activation of microglial $\mathrm{CB}_{2}$ receptors has been shown to be neuroprotective and improve motor symptoms in several animal models of PD (Price et al., 2009; Chung et al., 2016; Cassano et al., 2017). A naturally occurring $\mathrm{CB}_{2}$ receptor agonist, $\beta$ caryophyllene (BCP), was neuroprotective and dampened the pro-inflammatory response of microglia in rats in a rotenoneinduced model of PD (Javed et al., 2016; Ojha et al., 2016). Administration of WIN55,212-2 reduced neuronal death and improved motor symptoms in mice subjected to MPTPdependent neurotoxicity (Price et al., 2009). Treatment with WIN55,212-2 also reduced the number of M1 microglia in the ventral midbrain. An equal effect was observed within the same study upon administration of a $\mathrm{CB}_{2}$ receptor-selective agonist, JWH-015. Interestingly, the effects of WIN55,212-2 on microglial activation were completely blocked by the $\mathrm{CB}_{2}$ receptor-selective inverse agonist, JTE-907. These results were unchanged in $\mathrm{CB}_{1}$ receptor knockout mice, but the MPTP-dependent neurotoxicity was exacerbated in $\mathrm{CB}_{2}$ receptor knockout mice. Thus, the effects of WIN55,212-2 were likely mediated solely by $\mathrm{CB}_{2}$ receptors despite the nonselective nature of the ligand. Taken together, $\mathrm{CB}_{2}$ receptors, specifically on microglia, may represent a therapeutic target to reduce neuroinflammation and protect neurons through the development of PD.

\section{Huntington's Disease}

$\mathrm{HD}$ is an inherited disorder that is characterized by the progressive loss of dopaminergic neurons in the indirect pathway of the striatum which causes locomotor and cognitive impairments (Cristino et al., 2020). An increased abundance of activated microglia has been measured in the cortex and striatum in human HD brains compared to aged humans free of neurological disorder (Sapp et al., 2001). There was also a strong positive correlation between disease stage and the accumulation of primed proinflammatory microglia as measured by the abundance of MHC class II antigens (Sapp et al., 2001). Positron emission tomography has been used to measure a marked increase in the binding of radiolabeled PK11195 in cortical brain regions and in the striatum of patients with HD (Pavese et al., 2006; Yen F. Tai et al., 2007a). As PK-11195 is 
known to bind primarily to glial cells in the injured CNS, this would indicate that there was a substantial increase in the abundance of activated microglia in the human HD brain tissue (Cagnin et al., 2002). Pavese et al. (2006) also found that the degree of microglial activation correlated with disease stage which implicated a direct role of microglia in the progression of the disease. This group has used similar methodologies to determine that there was an elevated number of microglia in the striatum and cortex of pre-symptomatic carriers of the mutant HTT gene with abnormally expanded CAG repeats (Yen F. Tai et al., 2007b). The elevation in activated microglia was also correlated with decreased binding of ${ }^{11} \mathrm{C}$-raclopride, indicative of striatal neuron loss. These data indicate that the microglial response and neuronal dysfunction occur in tandem, several years prior to the predicted age of disease onset of HD based on the number of CAG repeats.

$\mathrm{HD}$ progression has been characterized by a loss of neuronal $\mathrm{CB}_{1}$ receptors in several transgenic mouse models as well as in postmortem human HD brains (Glass et al., 1993; Denovan-Wright and Robertson, 2000; Lastres-Becker et al., 2002; Dowie et al., 2009; Blázquez et al., 2011). Conversely, an upregulation of $\mathrm{CB}_{2}$ receptors has been observed in the striatum of R6/1 and R6/2 transgenic mice as well as human HD brains (Palazuelos et al., 2009). The immunolabeling revealed colocalization with ionized calciumbinding adapter molecule 1 (Iba1) but not glial fibrillary acidic protein (GFAP) which indicated that the receptors were specifically upregulated in microglia. Male Sprague Dawley rats that received an intrastriatal injection of malonate exhibited a 4-fold increase in $\mathrm{CB}_{2}$ receptor mRNA within the striatum (Sagredo et al., 2009). Many of the $\mathrm{CB}_{2}$ receptors were expressed in activated $\mathrm{M} 1$ microglia, although astrocytes were also identified as $\mathrm{CB}_{2}$ receptor positive. However, Dowie et al. (2014) reported that upregulation of $\mathrm{CB}_{2}$ receptor protein was localized to the vasculature and not microglia or astrocytes in human $\mathrm{HD}$ brain tissue. When R6/2 mice were crossed with $\mathrm{CB}_{2}$ receptor knockout mice, the offspring exhibited aggravated motor symptoms which indicates that constitutive $\mathrm{CB}_{2}$ receptor activity was beneficial to disease progression in this model (Palazuelos et al., 2009). The striata from these R6/2 mice had higher proportions of M1 microglia with elevated IL-1 $\beta$, IL-6, TNFa, and iNOS. Given these data, elevated microglial $\mathrm{CB}_{2}$ receptors may not have been simply induced by the proinflammatory state. Thus, $\mathrm{CB}_{2}$ receptors may regulate microglial activation and play a protective role in the context of $\mathrm{HD}$.

Based on current data, it appears that $\mathrm{CB}_{1}$ and $\mathrm{CB}_{2}$ receptors play important roles in $\mathrm{HD}$ to control excitotoxicity and neuroinflammation, respectively. Thus, the use of therapeutics to preserve $\mathrm{CB}_{1}$ receptors and activate $\mathrm{CB}_{2}$ receptors may be a useful strategy to treat symptoms of $\mathrm{HD}$. One method to preserve neuronal $\mathrm{CB}_{1}$ receptors appears was through stimulation of the receptors. Laprairie et al. (2013) determined that the selective $\mathrm{CB}_{1}$ receptor agonist, arachidonyl-2'-chloroethylamide (ACEA), upregulated neuronal expression of $\mathrm{CB}_{1}$ receptor mRNA and protein in the STHdh $h^{\mathrm{Q} 7 / \mathrm{Q} 7}$ and STHdh $h^{\mathrm{Q} 111 / \mathrm{Q} 111}$ cell models of HD. These effects were mediated by NF- $\kappa \mathrm{B}$ and Akt downstream of $\mathrm{CB}_{1}$ receptor activation. Sagredo et al. (2009) found that direct stimulation of $\mathrm{CB}_{1}$ receptors using ACEA did not improve the survival of striatal projection neurons following an acute neurotoxic malonate lesion in Sprague Dawley rats. There was also no benefit of $\Delta^{9}$-THC or HU-210 (synthetic nonselective agonist) to preserve $\mathrm{CB}_{1}$ receptors in the $\mathrm{R} 6 / 1$ mouse model of HD (Dowie et al., 2010). $\mathrm{CB}_{1}$ receptors are also limited as a therapeutic target due to the psychoactivity associated with global receptor activation (Ashton and Glass, 2007). A method to circumvent these limitations may be to use positive allosteric modulators to enhance $\mathrm{CB}_{1}$ receptor activation by endogenous cannabinoids. Positive allosteric modulators of $\mathrm{CB}_{1}$ receptors have shown to improve cell viability in a cell model of $\mathrm{HD}$ as well as improve motor coordination and delay symptom onset in R6/2 mice (Laprairie et al., 2019). Furthermore, inhibition of FAAH using URB597 preserved $\mathrm{CB}_{1}$ receptors in the striatum of R6/1 mice (Dowie et al., 2010). The $\mathrm{CB}_{2}$ receptor-selective agonist HU-308 has been neuroprotective and reduced the TNFa concentration in rats that received intrastriatal malonate injections (Sagredo et al., 2009). Otherwise, there is limited data to support the use of $\mathrm{CB}_{2}$ receptor-selective agonists specifically in HD. However, therapeutics that target microglial $\mathrm{CB}_{2}$ receptors to dampen the neuroinflammatory response have been generally promising for brain diseases with an inflammatory component (Navarro et al., 2016).

\section{Aging}

Even in the absence of disease, aging brains exhibit an elevation in the proportions of activated M1 microglia that secrete proinflammatory cytokines such as TNFa, IL-1 $\beta$, and IL-6 in the central nervous system; proportions of M2 microglia are also reduced which leads to a deficiency in anti-inflammatory cytokines such as IL-10 (Ye and Johnson, 1999; Ye and Johnson, 2001; Lukiw, 2004; Streit et al., 2004; Zahn et al., 2007). In brains of aged mice ( 20 months old), $25 \%$ of microglia have been reported to be MHC class II-positive compared to only $2 \%$ of microglia in healthy adult mice ( 4 months old) (Henry et al., 2009). Thus, a much larger proportion of microglia in aged mice were primed for proinflammatory activity compared to younger mice under otherwise healthy conditions (Norden and Godbout, 2013). A number of studies have demonstrated that aged mice are also more sensitive to inflammatory stimuli compared to adult mice (Wynne et al., 2010; Njie et al., 2012). Sierra et al. (2007) found that aged mice had an enhanced response to LPS injection and had higher expression of TNFa, IL-1 $\beta$, IL- 6 , and IL-12 mRNA in microglia compared to adult mice. Henry et al. (2009) also demonstrated that microglia isolated from aged mice exhibited elevated mRNA abundance for proinflammatory cytokine production. There were functional consequences to the elevation of these cytokines as the increased inflammatory properties of aged brains has been associated with psychomotor and cognitive impairment in mice (Weaver et al., 2002; Richwine et al., 2005; Hayashi et al., 2008; Villeda et al., 2011). The exaggerated immune response in elderly populations has also been associated with increased susceptibility to behavioural complications following peripheral immune challenge, including depression and cognitive impairment (Godbout and Johnson, 2006; Godbout and Johnson, 2009; Corona et al., 2012). 
The balance of microglial phenotypes has been found to change with age toward an increase in pro-inflammatory phenotypes, with the emergence of some transcriptional phenotypes not observed in younger mice (Hammond et al., 2019). Microglia from aged mice (24-month old) exhibited markers of pro-inflammation, including upregulation of markers of cytokine release and phagocytosis (Raj et al., 2017). Microglia from aged animals also differed substantially from those of young animals in terms of metabolism, potentially due to differences in rapamycin-insensitive companion of mTOR (RICTOR) which was a common upstream regulator of many of the dysregulated metabolic processes (Flowers et al., 2017). Interestingly, cultured BV-2 microglia in the absence of RICTOR exhibited the same phenotype as primary microglia from aged animals. This may indicate that microglial metabolic dysregulation with age can cause multiple phenotypes to converge.

As aged brains exhibit a higher proportion of proinflammatory microglia compared to young brains, it would be expected for aged brains to contain elevated levels of $\mathrm{CB}_{2}$ receptors as well. However, Hodges et al. (2020) reported no statistically significant differences in $\mathrm{CB}_{2}$ receptor mRNA from the cortex or hypothalamus between young and aged mice. In contrast, Pascual et al. (2014) reported decreased $\mathrm{CB}_{2}$ receptor abundance in aged rats. Aged rats (24-month old) exhibited a $50 \%$ reduction in $\mathrm{CB}_{1}$ receptor mRNA in the basal ganglia compared to young rats (3-month old) as measured by autoradiography and in situ hybridization (Mailleux and Vanderhaeghen, 1992; Romero et al., 1998). However, this early work did not determine whether the loss of $\mathrm{CB}_{1}$ receptor mRNA occurred only in neurons or in microglia as well.

Stimulation of $\mathrm{CB}_{2}$ receptors appeared to contribute to the control of neurogenesis in an age-dependent manner (Goncalves et al., 2008). The authors found that a DAGL inhibitor, RHC80267, inhibited the proliferation of Cor1 neural stem cell line which highlights the importance of $2-A G$ signaling in the proliferation of cultured neuronal stem cells. Goncalves et al. (2008) also demonstrated that selective antagonists for both $\mathrm{CB}_{1}$ receptors (AM251) and $\mathrm{CB}_{2}$ receptors (AM630) inhibited proliferation in the same cell line which suggested that the role of $2-A G$ in cell proliferation could be mediated by the actions of both $\mathrm{CB}_{1}$ and $\mathrm{CB}_{2}$ receptors. These results were consistent when the experiments were repeated in 6-week, 6month, and 20-month-old female mice. Stimulation of $\mathrm{CB}_{2}$ receptors via JWH-133 also increased the number of neurons in the subventricular zone, and the effects were most pronounced in the aged mice (Goncalves et al., 2008). Thus, the benefits of $\mathrm{CB}_{2}$ receptor activation could translate to an aging population.

\section{POTENTIAL INFLUENCE OF SEX AND EXERCISE ON ENDOCANNABINOID FUNCTION}

There are sex differences in the endocannabinoid system which impacts the responses to cannabinoids. In mice, females have reported higher quantities of both $\mathrm{CB}_{1}$ and $\mathrm{CB}_{2}$ receptor mRNA relative to males (Xing et al., 2014). This may partially explain the growing body of evidence that has demonstrated a greater effect of cannabinoids in females for the treatment of pain (Craft et al., 2013; Blanton et al., 2021). Microglia in the spinal cord sensitized male mice to neuropathic and inflammatory pain via TLR4, but the effects were not observed in female mice (Sorge et al., 2011). It was later determined that pain hypersensitivity in female mice was mediated by adaptive immune cells and not microglia (Sorge et al., 2015). Female mice also had greater quantities of microglia in the periaqueductal gray region of the brain which is involved in descending pain modulation (Doyle et al., 2017). This difference in number of microglia was proposed to explain the sex differences in the effectiveness of morphine for pain relief. As morphine interacts with microglial TLR4 to initiate a proinflammatory response, this may stimulate neuroinflammation which would counteract the analgesic effects (Hutchinson et al., 2010). Therefore, there are apparent inherent sex differences in microglia with respect to pain processing. To our knowledge, the connection between sex differences in cannabinoid receptor quantities and microglial distribution has not been investigated with respect to neuroinflammation. However, this information will be critical to tailor $\mathrm{CB}_{2}$ receptor-targeted therapies for the treatment of neuroinflammation.

The endocannabinoid system, and especially $\mathrm{CB}_{1}$ receptors in peripheral tissues, become dysregulated with lifestyle related diseases such as obesity (Matias et al., 2008). High-fat diets associated with obesity lead to higher quantities of circulating endocannabinoids and increased $\mathrm{CB}_{1}$ receptor activation which drove increased food intake and reduced insulin sensitivity and energy metabolism in skeletal muscle (Pagotto et al., 2006). Selective $C_{1}$ receptor antagonists have been in development as anti-obesity agents, however, these drugs include several negative side effects which has precluded their clinical use (Quarta and Cota, 2020). Interestingly, lifestyle interventions such as consistent exercise appear to counteract the overexpression of $\mathrm{CB}_{1}$ receptors in peripheral tissues (Heyman et al., 2012). Consistent exercise was also associated with improvements in cognition for $\mathrm{AD}$ patients, although a link to endocannabinoid-mediated mechanism has not been established to our knowledge (Meng et al., 2020).

\section{MECHANISMS OF $\mathrm{CB}_{2}$ RECEPTOR-MEDIATED EFFECTS IN MICROGLIA}

Activation of cannabinoid receptors has consistently been observed to dampen the shift of microglia to an M1 phenotype following treatment with a pro-inflammatory stimulus such as LPS or IFN $\gamma$ by inhibiting the release of soluble factors including NO, TNFa, and IL-6 (Tanaka et al., 2020). Activation of $\mathrm{CB}_{2}$ receptors also appears to regulate the shift from an unreactive phenotype to an anti-inflammatory M2 phenotype. It is possible that cannabinoids also facilitate a shift from an M1 phenotype directly to an M2 phenotype. Although there is a clear relationship based on the profiles of cytokines released from the microglia, the specific mechanisms and 
signaling pathways involved have not been thoroughly examined. Recent evidence has implicated the MAPK pathways as potential targets to explain the relationship between cannabinoid signaling and inflammation.

MAPKs are intracellular signaling proteins that are responsible for many downstream functions and can be subdivided into c-Jun N-terminal Kinase (JNK), extracellular signal-regulated kinase (ERK), and p38 proteins. Each of the MAPK signaling pathways has also been associated with both the pro-inflammatory and anti-inflammatory properties of microglia (Kim et al., 2004; Waetzig et al., 2005; Bachstetter et al., 2011; Li et al., 2019; Chen et al., 2021). As both $\mathrm{CB}_{1}$ and $\mathrm{CB}_{2}$ receptors typically couple to $\mathrm{Ga}_{\mathrm{i} / \mathrm{o}}$ and $\mathrm{G} \beta \gamma$ proteins, activation of these receptors typically initiates phosphorylation of downstream MAPK pathways (Bouaboula et al., 1996; Howlett et al., 2002; Komorowska-Müller and Schmöle, 2020). Correa et al. (2011) found that treatment with AEA dampened the release of proinflammatory cytokines IL-12 and IL-23 in a mouse model of multiple sclerosis via the JNK and ERK1/2 pathways, but the effect was only partially mediated by $\mathrm{CB}_{2}$ receptors. The inhibitory effects of AEA on the release of TNFa, IL-6, and IL- $1 \beta$ were fully blocked by a PKC inhibitor, chelerythrine, which indicated that both $\mathrm{CB}_{1}$ and $\mathrm{CB}_{2}$ receptors may have contributed via MAPK signaling (Ma et al., 2015). Recent transcriptomic data using $\mathrm{CB}_{2}$ receptor knockout microglia demonstrated impaired MAPK signaling which corroborated the involvement of $\mathrm{CB}_{2}$ receptors in these pathways (Reusch et al., 2021). Activation of $\mathrm{CB}_{2}$ receptors has also been shown to reduce translocation of NF$\kappa \mathrm{B}$ p65 to the nucleus, perhaps as a downstream consequence of MAPK signaling (Correa et al., 2010; Javed et al., 2016).

Pro-inflammatory stimuli such as LPS and IFN $\gamma$ have been reported to initiate MAPK signaling in microglia (Frazier et al., 2012; Meng et al., 2014). $\mathrm{CB}_{2}$ receptor activation diminished the downstream translation of pro-inflammatory cytokine genes in cultured microglia challenged with $A \beta_{1-42}$ (Ehrhart et al., 2005). Thus, it seems that there is negative cross-talk among $\mathrm{CB}_{2}$ receptor signaling and LPS- or IFN $\gamma$-dependent MAPK signaling. Although ERK phosphorylation was induced independently by LPS and $\mathrm{CB}_{2}$ receptor activation in cultured BV-2 microglia, co-treatment with LPS and AEA or WIN$55,212,-2$ induced a much smaller effect than either stimulus alone (Eljaschewitsch et al., 2006). This appears to be caused by the induction of MAPK phosphatase (MKP)-1/2 which dephosphorylated ERK1/2. As the induction of MKP-1 occurred much faster in the presence of LPS and AEA compared to either compound alone, LPS-mediated ERK phosphorylation was blunted. The effect of AEA was partially blocked by AM251 but fully blocked by AM630 (Eljaschewitsch et al., 2006). This indicated that both $\mathrm{CB}_{1}$ and $\mathrm{CB}_{2}$ receptors may have contributed to the inhibition of microglial proinflammatory phenotypes. Subsequent work has corroborated that $\mathrm{CB}_{2}$ receptor activation induced MKP-1 and MKP-3 which inhibited ERK phosphorylation upon LPS stimulation in primary rat microglia (Romero-Sandoval et al., 2009). Thus, it seems likely that $\mathrm{CB}_{2}$ receptor activation attenuates LPS-induced ERK phosphorylation and downstream transcription of proinflammatory genes through the induction of MKP proteins.
Further investigation of endocannabinoid-mediated upregulation of MKP proteins may provide important clues into how $\mathrm{CB}_{2}$ receptor agonism can inhibit the activation of pro-inflammatory microglia.

Acquisition of immunomodulatory M2-like properties in microglia has been observed following $\mathrm{CB}_{2}$ receptor-dependent MAPK signaling. Cultured BV-2 microglia treated with LPS and IFN $\gamma$ demonstrated elevated release of the anti-inflammatory cytokine IL-10 release, this was enhanced by co-incubation with AEA in a dose-dependent manner (Correa et al., 2010). A similar effect was observed when the microglia were coincubated with the $\mathrm{CB}_{2}$ receptor-selective agonist, JWH-133. These effects were blocked by the $\mathrm{CB}_{2}$ receptor-selective antagonist, SR144528, but not influenced by the $\mathrm{CB}_{1}$ receptorselective antagonist, SR141716A. This indicated that the enhanced effect on IL-10 release was mediated by the activation of $\mathrm{CB}_{2}$ but not $\mathrm{CB}_{1}$ receptors. Furthermore, the effects were blocked by the MEK1/2 inhibitor, PD98059, as well as the JNK inhibitor, SP600125. However, the PI3K/Akt inhibitor, Ly294002, had no influence over the effects (Correa et al., 2010). Thus, it appears that $\mathrm{CB}_{2}$ receptor activation can promote the downstream release of anti-inflammatory factors such as IL-10 via the ERK and JNK MAPK pathways. This could allow microglia in a pro-inflammatory phenotype to also acquire M2-like properties following $\mathrm{CB}_{2}$ receptor activation.

Non-canonical cAMP-mediated signaling pathways may also contribute to the anti-inflammatory properties of cannabinoids in microglia. $\mathrm{CB}_{2}$ receptors generally couple to $\mathrm{Ga}_{\mathrm{i}}$ proteins and do not mediate increased cAMP (Glass and Northup, 1999; Ibsen et al., 2017). However, there is recent evidence to suggest that $\mathrm{CB}_{2}$ receptors could couple to $\mathrm{Ga}_{\mathrm{s}}$ proteins in primary human peripheral blood mononuclear cells to elevate cAMP and activate PKA (Saroz et al., 2019). In cultured primary rat microglia treated with thrombin, co-treatment with JWH-133 caused an increase in cAMP accumulation in a dose-dependent manner (Tao et al., 2016). JWH-133 treatment also increased the downstream phosphorylation of PKA as a consequence of elevated cAMP (Tao et al., 2016). This elevation in phosphorylated PKA mediated a reduction in mRNA for proinflammatory markers such as CD68, TNFa, IL-1 $\beta$, and IFN $\gamma$. Thrombin generally binds to $\mathrm{Ga}_{\mathrm{i}}$ protein-coupled receptors such as protease-activated receptor (PAR)-1 and PAR-4 to inhibit cAMP accumulation (Simonds et al., 1989). As both PARs and $\mathrm{CB}_{2}$ receptors typically inhibit adenylate cyclase, it appears that there is an alteration in the signaling properties when both receptors are co-activated. This observation of cAMP accumulation upon co-treatment with thrombin and JWH-133 could be an early example of $\mathrm{Ga}_{\mathrm{s}}$ protein-coupled $\mathrm{CB}_{2}$ receptors in microglia.

\section{POTENTIAL INFLUENCE OF $\mathrm{CB}_{2}$ RECEPTOR HETEROMERS}

Cannabinoid receptors have been found to form oligomeric receptor complexes, known as heteromers, with several other class A GPCRs such as adenosine receptors (Carriba et al., 2007; 


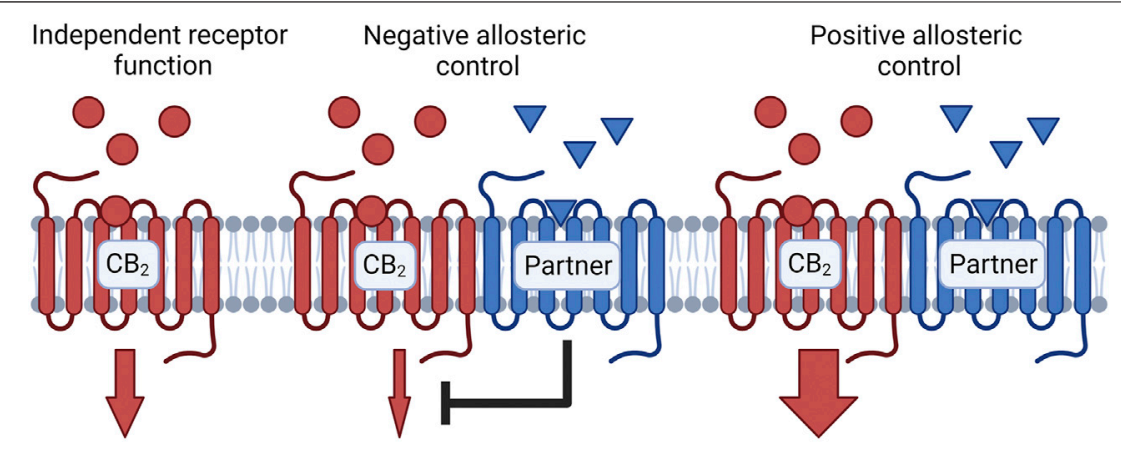

Agonist of $\mathrm{CB} 2$ receptors

$\checkmark$ Agonist or antagonist of partner receptors

FIGURE 2| Schematic representation of signaling changes due to $\mathrm{CB}_{2}$ receptor heteromer formation. When presented with an agonist or antagonist for the partner receptor, the partner receptor may exert negative allosteric control over $\mathrm{CB}_{2}$ receptors which results in reduced signaling from the $\mathrm{CB}_{2}$ receptor relative to the $\mathrm{CB}_{2}$ receptor which does not participate in a heteromeric complex. Conversely, a partner receptor may exert positive allosteric control over the $\mathrm{CB}_{2}$ receptor which enhances signaling from the $\mathrm{CB}_{2}$ receptor mediated by the $\mathrm{CB}_{2}$ receptor agonist. Figure created with BioRender.

Aso et al., 2019; Franco et al., 2019a; Köfalvi et al., 2020) and serotonin receptors (Franco et al., 2019b). Interestingly, cannabinoid receptor heteromers exhibit distinct signaling properties compared to the individual receptors alone (Callén et al., 2012; Balenga et al., 2014; Navarro et al., 2018). $\mathrm{CB}_{2}-\mathrm{A}_{2 \mathrm{~A}}$, $\mathrm{CB}_{2}-5 \mathrm{HT}_{1 \mathrm{~A}}$, and $\mathrm{CB}_{2}-\mathrm{CB}_{1}$ heteromers have been observed within microglia and fundamentally alter the microglial response to cannabinoids (Navarro et al., 2018; Franco et al., 2019a; Franco et al., 2019b). Furthermore, these heteromers have been found in different quantities under conditions of neuroinflammation and in response to different cannabinoid treatments (Navarro et al., 2018; Bagher et al., 2020). Currently, there are several established heteromer-dependent mechanisms that can result in either enhanced or diminished $\mathrm{CB}_{2}$ receptor-mediated signaling (Figure 2). These mechanisms will be important to consider through the development of $\mathrm{CB}_{2}$ receptor-selective molecules for the treatment of neuroinflammation.

Cross-antagonism is a form of allosteric control within $\mathrm{CB}_{2}$ receptor heteromers that involves diminished signaling from the $\mathrm{CB}_{2}$ receptors upon antagonism of the partner receptor. This is often a bidirectional phenomenon where an antagonist for the $\mathrm{CB}_{2}$ receptors would also block activity of the partner receptor. For example, $\mathrm{CB}_{2}$ receptor-mediated $\mathrm{Akt} / \mathrm{PKB}$ phosphorylation has been inhibited in the presence of the $\mathrm{CB}_{1}$ receptor-selective antagonist AM251 in cells that co-expressed both receptors (Callén et al., 2012). Serotonin type 1A $\left(5 \mathrm{HT}_{1 \mathrm{~A}}\right)$ receptors exert similar effects as the antagonist WAY-100635 has been observed to diminish $\mathrm{CB}_{2}$ receptor-mediated ERK phosphorylation when co-administered with the $\mathrm{CB}_{2}$ receptor agonist PM224 (Franco et al., 2019b). Interestingly, adenosine type $2 \mathrm{~A}\left(\mathrm{~A}_{2 \mathrm{~A}}\right)$ receptors enhanced $\mathrm{CB}_{2}$ receptor signaling in microglia where the receptors co-expressed (Franco et al., 2019a). Franco et al. (2019a) determined that treatment of microglia with an $\mathrm{A}_{2 \mathrm{~A}}$ receptor antagonist (SCH58621) resulted in an enhanced effect of $\mathrm{CB}_{2}$ receptor-mediated cAMP inhibition compared to agonism of $\mathrm{CB}_{2}$ receptors alone. Ultimately, it appears that a blockade of $5 \mathrm{HT}_{1 \mathrm{~A}}$ receptors diminishes $\mathrm{CB}_{2}$ receptor-mediated signaling whereas an antagonist for $\mathrm{A}_{2 \mathrm{~A}}$ receptors may facilitate an enhanced effect of cannabinoid treatments. Given this contrast, it can be difficult to predict how $\mathrm{CB}_{2}$ receptor signaling could be affected in the presence of an antagonist for another GPCR that could form heteromers with $\mathrm{CB}_{2}$ receptors.

When $\mathrm{CB}_{2}$ receptor heteromers are presented with agonists for both receptors simultaneously, the effects of the ligands may produce different effects compared to either of the agonists alone. Diminished Akt phosphorylation was observed in transfected SH-SY5Y cells upon treatment with a $\mathrm{CB}_{1}$ receptor agonist (ACEA) and a $\mathrm{CB}_{2}$ receptor agonist (JWH-133) relative to treatment with either ACEA or JWH-133 alone (Callén et al., 2012). A similarly diminished effect on ERK phosphorylation has been observed upon co-treatment with JWH-133 and an $\mathrm{A}_{2 \mathrm{~A}}$ receptor agonist (CGS-21680) (Franco et al., 2019a). In contrast, co-treatment with $\mathrm{PM} 224$ and a $5 \mathrm{HT}_{1 \mathrm{~A}}$ receptor agonist $(8-\mathrm{OH}-$ DPAT) produced an enhanced effect on ERK phosphorylation in co-transfected cells compared to either agonist alone (Franco et al., 2019b). Thus, coactivation of $\mathrm{CB}_{2}$ receptors and $\mathrm{A}_{2 \mathrm{~A}}$ receptors may diminish the effects of $\mathrm{CB}_{2}$ receptor agonists whereas coactivation with $5 \mathrm{HT}_{1 \mathrm{~A}}$ receptors may lead to enhanced cannabinoid-mediated effects.

\section{RECENT DEVELOPMENTS AND CURRENT CHALLENGES}

It has become clear that there is an association between neurodegenerative diseases and the presence of proinflammatory microglia which propagate the process of neuroinflammation. However, it has been difficult to 
determine whether the microglia are involved in the development of these pathological conditions or simply responding to the damage. It has been proposed that microglia react to neurodegeneration to initiate neuroinflammation which exacerbates the damage, but there is emerging evidence which suggests that aberrant microglial activity could contribute to the development of such diseases. The erasure of microglia from R6/2 HD mice using a CSF1 antagonist promoted the maintenance of cognitive function and striatal neurite density and prevented the onset of some disease symptoms including loss of grip strength and striatal atrophy (Crapser et al., 2020). This would indicate that the microglia within the mouse HD brains induced damage that was ameliorated upon microglial depletion. Microglia expressing mutant huntingtin have been observed to be hyperreactive and released elevated quantities of proinflammatory cytokines at baseline (Crotti et al., 2014). This makes it difficult to distinguish between a potential detrimental effect of normal microglia compared to the neuroinflammation initiated by the mutant microglia. Similar benefits have been found upon depletion of microglia in $\mathrm{AD}$ mouse models (Spangenberg et al., 2016; Spangenberg et al., 2019). 5xFAD mice that received a CSF1 antagonist for 4 weeks maintained greater neuronal density compared to the vehicle treatment without alterations to $\mathrm{A} \beta$ levels (Spangenberg et al., 2016). Similar experiments were performed in younger mice prior to $\mathrm{A} \beta$ plaque development. These experiments revealed a lack of $A \beta$ development in animals that received a CSF1 antagonist, however, $A \beta$ plaques began to develop with microglial repopulation upon removal of the drug treatment (Spangenberg et al., 2019). These emerging data demonstrate that diseased microglia likely contribute to the progression of some neurodegenerative diseases, and that early targeting of these cells could be beneficial to prevent these contributions.

Several strategies have been employed to target the endocannabinoid system for the treatment of inflammation and neurodegeneration in humans. These strategies have primarily included combinations of phytocannabinoids, and synthetic $\mathrm{CB}_{2}$ receptor agonists. The most common method to engage the endocannabinoid system for the treatment of neuroinflammation or neurodegeneration has been with phytocannabinoids, including combinations of $\Delta^{9}$-THC and cannabidiol (CBD). Sativex ${ }^{\mathrm{TM}}$, which combines relatively equal amounts of $\Delta^{9}$-THC and CBD, has been tested in clinical trials for the treatment of HD (ClinicalTrials.gov identifier: NCT01502046). The results of the pilot cross-over trial indicated that Sativex ${ }^{\mathrm{TM}}$ was well tolerated in patients but there was no benefit to the disease progression (López-Sendón Moreno et al., 2016). Although Sativex ${ }^{\mathrm{TM}}$ has been approved for the treatment of neuropathic pain in multiple sclerosis, there is no clear clinical evidence that such phytocannabinoid-based drugs are useful specifically for the treatment of neuroinflammation in humans (ClinicalTrials.gov identifier: NCT00391079). Perhaps the most promising preclinical data has emerged from the use of synthetic selective $\mathrm{CB}_{2}$ receptor agonists to dampen the proinflammatory activity of microglia (Tanaka et al., 2020). Anabasum is a novel $\mathrm{CB}_{2}$ receptor agonist that is currently being trialed as an anti-inflammatory drug for use in cystic fibrosis, systemic sclerosis, dermatomyositis, and systemic lupus erythematosus (Clinicaltrial.gov identifiers: NCT02465450, NCT02465437, NCT02466243). Anabasum has recently demonstrated efficacy against a pro-inflammatory challenge in humans (Motwani et al., 2018). When ultraviolet light-killed Escherichia coli were injected intradermally into healthy individuals, anabasum treatment improved clearance of the pro-inflammatory stimulus and inhibited inflammation similar to prednisolone treatment. There was also enhanced biosynthesis of several pro-resolving lipid mediators (Motwani et al., 2018). This indicates that $\mathrm{CB}_{2}$ receptor agonists have potential to combat peripheral immune challenges in humans. Further work will be required to determine the potential effectiveness to combat inflammation in the brain.

The endocannabinoid system is emerging as a source of many therapeutically relevant targets for the treatment of inflammation and neurodegeneration. To further develop compounds to target the endocannabinoid system for clinical use, there are specific aspects of endocannabinoid function that require further attention. Great focus has been placed on the use of phytocannabinoids which engage an array of targets including $\mathrm{CB}_{1}$ receptors, $5 \mathrm{HT}_{1 \mathrm{~A}}$ receptors, and TRPV1 ion channels (Howlett et al., 2002; de Almeida and Devi, 2020). Basic research in the functions of the endocannabinoid system has revealed more specific targets such as $\mathrm{CB}_{2}$ receptors on microglia for the treatment of neuroinflammation (Ashton and Glass, 2007). There is mounting preclinical evidence for the use of $\mathrm{CB}_{2}$ receptor agonists to treat chronic and acute inflammation (Komorowska-Müller and Schmöle, 2020). However, there has been very little investigation into the therapeutic window for $\mathrm{CB}_{2}$ receptor agonists. It is still unclear whether it could be beneficial to pre-treat with $\mathrm{CB}_{2}$ receptor agonists for any amount of time to delay any potential onset symptoms of neurodegenerative disease. It is also unclear if $\mathrm{CB}_{2}$ receptor agonists become less effective once a certain degree of neurodegeneration and microglial activation has been reached. Improving our understanding of the temporal therapeutic window of these drugs will be critical to determine their viability in an emergency or clinical setting. We also lack in our basic understanding of the functions of microglial $\mathrm{CB}_{2}$ receptors as well as how these functions may change throughout the human lifespan or in different microglial populations. For example, in addition to the regulation of immune activity, $\mathrm{CB}_{2}$ receptors have been implicated in other fundamental functions of microglia such as the regulation of phagocytosis (Ehrhart et al., 2005; Mecha et al., 2015; Guida et al., 2017). Microglia have important roles in pruning of synapses during development and disease (Stevens et al., 2007; Schafer et al., 2012). Thus, activation of $\mathrm{CB}_{2}$ receptors at specific times could be either beneficial or greatly detrimental to healthy brain development. Ultimately, understanding the function of $\mathrm{CB}_{2}$ receptors and the endocannabinoid system during these specific timeframes will be critical in the development of effective treatments that regulate microglial activity to dampen inflammation.

\section{AUTHOR CONTRIBUTIONS}

The manuscript was conceived and written by AY. The manuscript was critically evaluated and edited by AY and 
ED-W. Both authors approved the submission of the manuscript.

\section{FUNDING}

This work was supported by the Natural Sciences and Engineering Research Council of Canada (NSERC) Discovery Grant (RGPIN37999-2019) to ED-W and an NSERC CGS-D to AY.

\section{REFERENCES}

Abbas, N., Bednar, I., Mix, E., Marie, S., Paterson, D., Ljungberg, A., et al. (2002). Up-Regulation of the Inflammatory Cytokines IFN-Gamma and IL-12 and Down-Regulation of IL-4 in Cerebral Cortex Regions of APP(SWE) Transgenic Mice. J. Neuroimmunol 126, 50-57. doi:10.1016/s0165-5728(02)00050-4

Alger, B. E., and Kim, J. (2011). Supply and Demand for Endocannabinoids. Trends Neurosci. 34, 304-315. doi:10.1016/j.tins.2011.03.003

Araujo, D. J., Tjoa, K., and Saijo, K. (2019). The Endocannabinoid System as a Window into Microglial Biology and its Relationship to Autism. Front Cel Neurosci 13, 424. doi:10.3389/fncel.2019.00424

Ashton, J. C., and Glass, M. (2007). The Cannabinoid CB2 Receptor as a Target for Inflammation-Dependent Neurodegeneration. Curr. Neuropharmacol 5, 73-80. doi:10.2174/157015907780866884

Aso, E., Juvés, S., Maldonado, R., and Ferrer, I. (2013). CB2 Cannabinoid Receptor Agonist Ameliorates Alzheimer-like Phenotype in AßPP/PS1 Mice. J. Alzheimers Dis. 35, 847-858. doi:10.3233/JAD-130137

Aso, E., Andrés-Benito, P., Carmona, M., Maldonado, R., and Ferrer, I. (2016). Cannabinoid Receptor 2 Participates in Amyloid- $\beta$ Processing in a Mouse Model of Alzheimer's Disease but Plays a Minor Role in the Therapeutic Properties of a Cannabis-Based Medicine. J. Alzheimers Dis. 51, 489-500. doi:10.3233/JAD-150913

Aso, E., Fernández-Dueñas, V., López-Cano, M., Taura, J., Watanabe, M., Ferrer, I., et al. (2019). Adenosine A2A-Cannabinoid CB1 Receptor Heteromers in the Hippocampus: Cannabidiol Blunts $\Delta 9$-Tetrahydrocannabinol-Induced Cognitive Impairment. Mol. Neurobiol. 56, 5382-5391. doi:10.1007/s12035018-1456-3

Bachiller, S., Jiménez-Ferrer, I., Paulus, A., Yang, Y., Swanberg, M., Deierborg, T., et al. (2018). Microglia in Neurological Diseases: A Road Map to Brain-Disease Dependent-Inflammatory Response. Front. Cel Neurosci 12, 488. doi:10.3389/ fncel.2018.00488

Bachstetter, A. D., Xing, B., de Almeida, L., Dimayuga, E. R., Watterson, D. M., and Van Eldik, L. J. (2011). Microglial P38a MAPK Is a Key Regulator of Proinflammatory Cytokine Up-Regulation Induced by Toll-Like Receptor (TLR) Ligands or Beta-Amyloid (A $\beta$ ). J. Neuroinflammation 8, 79. doi:10. 1186/1742-2094-8-79

Bagher, A. M., Young, A. P., Laprairie, R. B., Toguri, J. T., Kelly, M. E. M., and Denovan-Wright, E. M. (2020). Heteromer Formation between Cannabinoid Type 1 and Dopamine Type 2 Receptors Is Altered by Combination Cannabinoid and Antipsychotic Treatments. J. Neurosci. Res. 98, 2496-2509. doi:10.1002/jnr.24716

Balenga, N. A., Martínez-Pinilla, E., Kargl, J., Schröder, R., Peinhaupt, M., Platzer, W., et al. (2014). Heteromerization of GPR55 and Cannabinoid CB2 Receptors Modulates Signalling. Br. J. Pharmacol. 171, 5387-5406. doi:10.1111/bph.12850

Benito, C., Núñez, E., Tolón, R. M., Carrier, E. J., Rábano, A., Hillard, C. J., et al. (2003). Cannabinoid CB2 Receptors and Fatty Acid Amide Hydrolase Are Selectively Overexpressed in Neuritic Plaque-Associated Glia in Alzheimer's Disease Brains. J. Neurosci. 23, 11136-11141. doi:10.1523/jneurosci.23-3511136.2003

Benzing, W. C., Wujek, J. R., Ward, E. K., Shaffer, D., Ashe, K. H., Younkin, S. G., et al. (1999). Evidence for Glial-Mediated Inflammation in Aged APP(SW) Transgenic Mice. Neurobiol. Aging 20, 581-589. doi:10.1016/s0197-4580(99)00065-2

Blázquez, C., Chiarlone, A., Sagredo, O., Aguado, T., Pazos, M. R., Resel, E., et al. (2011). Loss of Striatal Type 1 Cannabinoid Receptors Is a Key Pathogenic Factor in Huntington's Disease. Brain 134, 119-136. doi:10.1093/brain/awq278

\section{SUPPLEMENTARY MATERIAL}

The Supplementary Material for this article can be found online at: https://www.frontiersin.org/articles/10.3389/fphar.2021.806417/ full\#supplementary-material

Supplementary Table S1 | Summary of the key changes that occur in the endocannabinoid system within several in vivo models or in human tissue with neurodegenerative diseases. Also noted is the impact of $\mathrm{CB}_{2}$ receptor activation in the animal model.

Blanton, H. L., Barnes, R. C., McHann, M. C., Bilbrey, J. A., Wilkerson, J. L., and Guindon, J. (2021). Sex Differences and the Endocannabinoid System in Pain. Pharmacol. Biochem. Behav. 202, 173107. doi:10.1016/j.pbb.2021.173107

Bloom, G. S. (2014). Amyloid- $\beta$ and Tau: The Trigger and Bullet in Alzheimer Disease Pathogenesis. JAMA Neurol. 71, 505-508. doi:10.1001/jamaneurol. 2013.5847

Bouaboula, M., Rinaldi, M., Carayon, P., Carillon, C., Delpech, B., Shire, D., et al. (1993). Cannabinoid-Receptor Expression in Human Leukocytes. Eur. J. Biochem. 214, 173-180. doi:10.1111/j.1432-1033.1993.tb17910.x

Bouaboula, M., Poinot-Chazel, C., Marchand, J., Canat, X., Bourrié, B., RinaldiCarmona, M., et al. (1996). Signaling Pathway Associated with Stimulation of CB2 Peripheral Cannabinoid Receptor. Involvement of Both MitogenActivated Protein Kinase and Induction of Krox-24 Expression. Eur. J. Biochem. 237, 704-711. doi:10.1111/j.1432-1033.1996.0704p.x

Cagnin, A., Gerhard, A., and Banati, R. B. (2002). The Concept of In Vivo Imaging of Neuroinflammation with [11C](R)-PK11195 PET. Ernst Schering Res. Found. Workshop 12, 179-191. doi:10.1007/978-3-662-05073-6_10

Callén, L., Moreno, E., Barroso-Chinea, P., Moreno-Delgado, D., Cortés, A., Mallol, J., et al. (2012). Cannabinoid Receptors CB1 and CB2 Form Functional Heteromers in Brain. J. Biol. Chem. 287, 20851-20865. doi:10.1074/jbc. M111.335273

Carlisle, S. J., Marciano-Cabral, F., Staab, A., Ludwick, C., and Cabral, G. A. (2002). Differential Expression of the CB2 Cannabinoid Receptor by Rodent Macrophages and Macrophage-Like Cells in Relation to Cell Activation. Int. Immunopharmacol 2, 69-82. doi:10.1016/S1567-5769(01)00147-3

Carriba, P., Ortiz, O., Patkar, K., Justinova, Z., Stroik, J., Themann, A., et al. (2007). Striatal Adenosine A2A and Cannabinoid CB1 Receptors Form Functional Heteromeric Complexes that Mediate the Motor Effects of Cannabinoids. Neuropsychopharmacology 32, 2249-2259. doi:10.1038/sj.npp.1301375

Cassano, T., Calcagnini, S., Pace, L., De Marco, F., Romano, A., and Gaetani, S. (2017). Cannabinoid Receptor 2 Signaling in Neurodegenerative Disorders: From Pathogenesis to a Promising Therapeutic Target. Front. Neurosci. 11, 30. doi:10.3389/fnins.2017.00030

Chen, M. J., Ramesha, S., Weinstock, L. D., Gao, T., Ping, L., Xiao, H., et al. (2021). Extracellular Signal-Regulated Kinase Regulates Microglial Immune Responses in Alzheimer's Disease. J. Neurosci. Res. 99, 1704-1721. doi:10.1002/jnr.24829

Cherry, J. D., Olschowka, J. A., and O'Banion, M. K. (2014a). Are "resting" microglia more "M2"? Front. Immunol. 5, 594. doi:10.3389/fimmu.2014.00594

Cherry, J. D., Olschowka, J. A., and O'Banion, M. K. (2014b). Neuroinflammation and M2 Microglia: The Good, the Bad, and the Inflamed. J. Neuroinflammation 11, 98. doi:10.1186/1742-2094-11-98

Chhor, V., Le Charpentier, T., Lebon, S., Oré, M. V., Celador, I. L., Josserand, J., et al. (2013). Characterization of Phenotype Markers and Neuronotoxic Potential of Polarised Primary Microglia In Vitro. Brain Behav. Immun. 32, 70-85. doi:10.1016/j.bbi.2013.02.005

Chung, Y. C., Shin, W. H., Baek, J. Y., Cho, E. J., Baik, H. H., Kim, S. R., et al. (2016). CB2 Receptor Activation Prevents Glial-Derived Neurotoxic Mediator Production, BBB Leakage and Peripheral Immune Cell Infiltration and Rescues Dopamine Neurons in the MPTP Model of Parkinson's Disease. Exp. Mol. Med. 48, e205. doi:10.1038/emm.2015.100

Corona, A. W., Fenn, A. M., and Godbout, J. P. (2012). Cognitive and Behavioral Consequences of Impaired Immunoregulation in Aging. J. Neuroimmune Pharmacol. 7, 7-23. doi:10.1007/s11481-011-9313-4

Correa, F., Hernangómez, M., Mestre, L., Loría, F., Spagnolo, A., Docagne, F., et al. (2010). Anandamide Enhances IL-10 Production in Activated Microglia by 
Targeting CB(2) Receptors: Roles of ERK1/2, JNK, and NF-kappaB. Glia 58, 135-147. doi:10.1002/glia.20907

Correa, F., Hernangómez-Herrero, M., Mestre, L., Loría, F., Docagne, F., and Guaza, C. (2011). The Endocannabinoid Anandamide Downregulates IL-23 and IL-12 Subunits in a Viral Model of Multiple Sclerosis: Evidence for a CrossTalk between IL-12p70/IL-23 Axis and IL-10 in Microglial Cells. Brain Behav. Immun. 25, 736-749. doi:10.1016/j.bbi.2011.01.020

Craft, R. M., Marusich, J. A., and Wiley, J. L. (2013). Sex Differences in Cannabinoid Pharmacology: A Reflection of Differences in the Endocannabinoid System? Life Sci. 92, 476-481. doi:10.1016/j.lfs.2012.06.009

Crapser, J. D., Ochaba, J., Soni, N., Reidling, J. C., Thompson, L. M., and Green, K. N. (2020). Microglial Depletion Prevents Extracellular Matrix Changes and Striatal Volume Reduction in a Model of Huntington's Disease. Brain 143, 266-288. doi:10.1093/brain/awz363

Cravatt, B. F., Demarest, K., Patricelli, M. P., Bracey, M. H., Giang, D. K., Martin, B. R., et al. (2001). Supersensitivity to Anandamide and Enhanced Endogenous Cannabinoid Signaling in Mice Lacking Fatty Acid Amide Hydrolase. Proc. Natl. Acad. Sci. U S A. 98, 9371-9376. doi:10.1073/pnas.161191698

Cristino, L., Bisogno, T., and Di Marzo, V. (2020). Cannabinoids and the Expanded Endocannabinoid System in Neurological Disorders. Nat. Rev. Neurol. 16, 9-29. doi:10.1038/s41582-019-0284-z

Crotti, A., Benner, C., Kerman, B. E., Gosselin, D., Lagier-Tourenne, C., Zuccato, C., et al. (2014). Mutant Huntingtin Promotes Autonomous Microglia Activation via Myeloid Lineage-Determining Factors. Nat. Neurosci. 17, 513-521. doi:10.1038/nn.3668

D'Andrea, M. R., Cole, G. M., and Ard, M. D. (2004). The Microglial Phagocytic Role with Specific Plaque Types in the Alzheimer Disease Brain. Neurobiol. Aging 25, 675-683. doi:10.1016/j.neurobiolaging.2003.12.026

de Almeida, D. L., and Devi, L. A. (2020). Diversity of Molecular Targets and Signaling Pathways for CBD. Pharmacol. Res. Perspect. 8, e00682. doi:10.1002/ prp2.682

Denovan-Wright, E. M., and Robertson, H. A. (2000). Cannabinoid Receptor Messenger RNA Levels Decrease in a Subset of Neurons of the Lateral Striatum, Cortex and Hippocampus of Transgenic Huntington's Disease Mice. Neuroscience 98, 705-713. doi:10.1016/s0306-4522(00)00157-3

Devane, W. A., Hanus, L., Breuer, A., Pertwee, R. G., Stevenson, L. A., Griffin, G., et al. (1992). Isolation and Structure of a Brain Constituent that Binds to the Cannabinoid Receptor. Science 258, 1946-1949. doi:10.1126/science.1470919

Di Marzo, V., Fontana, A., Cadas, H., Schinelli, S., Cimino, G., Schwartz, J. C., et al. (1994). Formation and Inactivation of Endogenous Cannabinoid Anandamide in Central Neurons. Nature 372, 686-691. doi:10.1038/372686a0

Di Marzo, V., Hill, M. P., Bisogno, T., Crossman, A. R., and Brotchie, J. M. (2000). Enhanced Levels of Endogenous Cannabinoids in the Globus Pallidus Are Associated with a Reduction in Movement in an Animal Model of Parkinson's Disease. FASEB J. 14, 1432-1438. doi:10.1096/fj.14.10.1432

Dowie, M. J., Bradshaw, H. B., Howard, M. L., Nicholson, L. F., Faull, R. L., Hannan, A. J., et al. (2009). Altered CB1 Receptor and Endocannabinoid Levels Precede Motor Symptom Onset in a Transgenic Mouse Model of Huntington's Disease. Neuroscience 163, 456-465. doi:10.1016/j.neuroscience.2009.06.014

Dowie, M. J., Howard, M. L., Nicholson, L. F., Faull, R. L., Hannan, A. J., and Glass, M. (2010). Behavioural and Molecular Consequences of Chronic Cannabinoid Treatment in Huntington's Disease Transgenic Mice. Neuroscience 170, 324-336. doi:10.1016/j.neuroscience.2010.06.056

Dowie, M. J., Grimsey, N. L., Hoffman, T., Faull, R. L., and Glass, M. (2014). Cannabinoid Receptor CB2 Is Expressed on Vascular Cells, but Not Astroglial Cells in the Post-Mortem Human Huntington's Disease Brain. J. Chem. Neuroanat. 59-60, 62-71. doi:10.1016/j.jchemneu.2014.06.004

Doyle, H. H., Eidson, L. N., Sinkiewicz, D. M., and Murphy, A. Z. (2017). Sex Differences in Microglia Activity within the Periaqueductal Gray of the Rat: A Potential Mechanism Driving the Dimorphic Effects of Morphine. J. Neurosci. 37, 3202-3214. doi:10.1523/JNEUROSCI.2906-16.2017

Ehrhart, J., Obregon, D., Mori, T., Hou, H., Sun, N., Bai, Y., et al. (2005). Stimulation of Cannabinoid Receptor 2 (CB2) Suppresses Microglial Activation. J. Neuroinflammation 2, 29. doi:10.1186/1742-2094-2-29

Eljaschewitsch, E., Witting, A., Mawrin, C., Lee, T., Schmidt, P. M., Wolf, S., et al. (2006). The Endocannabinoid Anandamide Protects Neurons during CNS Inflammation by Induction of MKP-1 in Microglial Cells. Neuron 49, 67-79. doi:10.1016/j.neuron.2005.11.027
Esposito, G., Iuvone, T., Savani, C., Scuderi, C., De Filippis, D., Papa, M., et al. (2007). Opposing Control of Cannabinoid Receptor Stimulation on AmyloidBeta-Induced Reactive Gliosis: In Vitro and In Vivo Evidence. J. Pharmacol. Exp. Ther. 322, 1144-1152. doi:10.1124/jpet.107.121566

Fakhfouri, G., Ahmadiani, A., Rahimian, R., Grolla, A. A., Moradi, F., and Haeri, A. (2012). WIN55212-2 Attenuates Amyloid-Beta-Induced Neuroinflammation in Rats through Activation of Cannabinoid Receptors and PPAR- $\gamma$ Pathway. Neuropharmacology 63, 653-666. doi:10.1016/j.neuropharm.2012.05.013

Felder, C. C., Briley, E. M., Axelrod, J., Simpson, J. T., Mackie, K., and Devane, W. A. (1993). Anandamide, an Endogenous Cannabimimetic Eicosanoid, Binds to the Cloned Human Cannabinoid Receptor and Stimulates Receptor-Mediated Signal Transduction. Proc. Natl. Acad. Sci. U S A. 90, 7656-7660. doi:10.1073/ pnas. 90.16 .7656

Flowers, A., Bell-Temin, H., Jalloh, A., Stevens, S. M., and Bickford, P. C. (2017). Proteomic Analysis of Aged Microglia: Shifts in Transcription, Bioenergetics, and Nutrient Response. J. Neuroinflammation. 14, 96. doi:10.1186/s12974-0170840-7

Franco, R., Reyes-Resina, I., Aguinaga, D., Lillo, A., Jiménez, J., Raïch, I., et al. (2019a). Potentiation of Cannabinoid Signaling in Microglia by Adenosine A 2A Receptor Antagonists. Glia 67, 2410-2423. doi:10.1002/glia.23694

Franco, R., Villa, M., Morales, P., Reyes-Resina, I., Gutiérrez-Rodríguez, A., Jiménez, J., et al. (2019b). Increased Expression of Cannabinoid CB2 and Serotonin 5-HT1A Heteroreceptor Complexes in a Model of Newborn Hypoxic-Ischemic Brain Damage. Neuropharmacology 152, 58-66. doi:10. 1016/j.neuropharm.2019.02.004

Frautschy, S. A., Yang, F., Irrizarry, M., Hyman, B., Saido, T. C., Hsiao, K., et al. (1998). Microglial Response to Amyloid Plaques in APPsw Transgenic Mice. Am. J. Pathol. 152, 307-317.

Frazier, W. J., Xue, J., Luce, W. A., and Liu, Y. (2012). MAPK Signaling Drives Inflammation in LPS-Stimulated Cardiomyocytes: The Route of Crosstalk to G-Protein-Coupled Receptors. PLOS ONE 7, e50071. doi:10.1371/journal.pone. 0050071

Galiègue, S., Mary, S., Marchand, J., Dussossoy, D., Carrière, D., Carayon, P., et al. (1995). Expression of Central and Peripheral Cannabinoid Receptors in Human Immune Tissues and Leukocyte Subpopulations. Eur. J. Biochem. 232, 54-61. doi:10.1111/j.1432-1033.1995.tb20780.x

Gerhard, A., Pavese, N., Hotton, G., Turkheimer, F., Es, M., Hammers, A., et al. (2006). In Vivo imaging of Microglial Activation with [11C](R)-Pk11195 PET in Idiopathic Parkinson's Disease. Neurobiol. Dis. 21, 404-412. doi:10.1016/j. nbd.2005.08.002

Glass, M., and Felder, C. C. (1997). Concurrent Stimulation of Cannabinoid CB1 and Dopamine D2 Receptors Augments cAMP Accumulation in Striatal Neurons: Evidence for a Gs Linkage to the CB1 Receptor. J. Neurosci. 17, 5327-5333. doi:10.1523/jneurosci.17-14-05327.1997

Glass, M., and Northup, J. K. (1999). Agonist Selective Regulation of G Proteins by Cannabinoid $\mathrm{CB}(1)$ and $\mathrm{CB}(2)$ Receptors. Mol. Pharmacol. 56, 1362-1369. doi:10.1124/mol.56.6.1362

Glass, M., Faull, R. L., and Dragunow, M. (1993). Loss of Cannabinoid Receptors in the Substantia Nigra in Huntington's Disease. Neuroscience 56, 523-527. doi:10. 1016/0306-4522(93)90352-g

Gómez-Gálvez, Y., Palomo-Garo, C., Fernández-Ruiz, J., and García, C. (2016). Potential of the Cannabinoid CB2 Receptor as a Pharmacological Target against Inflammation in Parkinson's Disease. Prog. Neuro-Psychopharmacology Biol. Psychiatry 64, 200-208. doi:10.1016/j.pnpbp.2015.03.017

Gobbi, G., Bambico, F. R., Mangieri, R., Bortolato, M., Campolongo, P., Solinas, M., et al. (2005). Antidepressant-Like Activity and Modulation of Brain Monoaminergic Transmission by Blockade of Anandamide Hydrolysis. Proc. Natl. Acad. Sci. U S A. 102, 18620-18625. doi:10.1073/pnas.0509591102

Godbout, J. P., and Johnson, R. W. (2006). Age and Neuroinflammation: A Lifetime of Psychoneuroimmune Consequences. Neurol. Clin. 24, 521-538. doi:10.1016/j.ncl.2006.03.010

Godbout, J. P., and Johnson, R. W. (2009). Age and Neuroinflammation: A Lifetime of Psychoneuroimmune Consequences. Immunol. Allergy Clin. North. Am. 29, 321-337. doi:10.1016/j.iac.2009.02.007

Goncalves, M. B., Suetterlin, P., Yip, P., Molina-Holgado, F., Walker, D. J., Oudin, M. J., et al. (2008). A Diacylglycerol Lipase-CB2 Cannabinoid Pathway Regulates Adult Subventricular Zone Neurogenesis in an Age-Dependent Manner. Mol. Cel Neurosci 38, 526-536. doi:10.1016/j.mcn.2008.05.001 
Griffin, G., Wray, E. J., Tao, Q., McAllister, S. D., Rorrer, W. K., Aung, M. M., et al. (1999). Evaluation of the Cannabinoid CB2 Receptor-Selective Antagonist, SR144528: Further Evidence for Cannabinoid CB2 Receptor Absence in the Rat Central Nervous System. Eur. J. Pharmacol. 377, 117-125. doi:10.1016/S00142999(99)00402-1

Guida, F., Luongo, L., Boccella, S., Giordano, M. E., Romano, R., Bellini, G., et al. (2017). Palmitoylethanolamide Induces Microglia Changes Associated with Increased Migration and Phagocytic Activity: Involvement of the CB2 Receptor. Sci. Rep. 7, 375. doi:10.1038/s41598-017-00342-1

Guzman-Martinez, L., Maccioni, R. B., Andrade, V., Navarrete, L. P., Pastor, M. G., and Ramos-Escobar, N. (2019). Neuroinflammation as a Common Feature of Neurodegenerative Disorders. Front. Pharmacol. 10, 1008. doi:10.3389/fphar. 2019.01008

Halleskog, C., Mulder, J., Dahlström, J., Mackie, K., Hortobágyi, T., Tanila, H., et al. (2011). WNT Signaling in Activated Microglia Is Proinflammatory. Glia 59, 119-131. doi:10.1002/glia.21081

Hammond, T. R., Dufort, C., Dissing-Olesen, L., Giera, S., Young, A., Wysoker, A., et al. (2019). Single-Cell RNA Sequencing of Microglia throughout the Mouse Lifespan and in the Injured Brain Reveals Complex Cell-State Changes. Immunity 50, 253-271. doi:10.1016/j.immuni.2018.11.004

Hayashi, Y., Yoshida, M., Yamato, M., Ide, T., Wu, Z., Ochi-Shindou, M., et al. (2008). Reverse of Age-Dependent Memory Impairment and Mitochondrial DNA Damage in Microglia by an Overexpression of Human Mitochondrial Transcription Factor a in Mice. J. Neurosci. 28, 8624-8634. doi:10.1523/ JNEUROSCI.1957-08.2008

Heneka, M. T., Carson, M. J., El Khoury, J., Landreth, G. E., Brosseron, F., Feinstein, D. L., et al. (2015). Neuroinflammation in Alzheimer's Disease. Lancet Neurol. 14, 388-405. doi:10.1016/S1474-4422(15)70016-5

Henry, C. J., Huang, Y., Wynne, A. M., and Godbout, J. P. (2009). Peripheral Lipopolysaccharide (LPS) challenge Promotes Microglial Hyperactivity in Aged Mice that Is Associated with Exaggerated Induction of Both Pro-Inflammatory IL-1beta and Anti-Inflammatory IL-10 Cytokines. Brain Behav. Immun. 23, 309-317. doi:10.1016/j.bbi.2008.09.002

Heyman, E., Gamelin, F. X., Aucouturier, J., and Di Marzo, V. (2012). The Role of the Endocannabinoid System in Skeletal Muscle and Metabolic Adaptations to Exercise: Potential Implications for the Treatment of Obesity. Obes. Rev. 13, 1110-1124. doi:10.1111/j.1467-789X.2012.01026.x

Hickman, S. E., Allison, E. K., and El Khoury, J. (2008). Microglial Dysfunction and Defective Beta-Amyloid Clearance Pathways in Aging Alzheimer's Disease Mice. J. Neurosci. 28, 8354-8360. doi:10.1523/JNEUROSCI.0616-08.2008

Hillard, C. J., Weinlander, K. M., and Stuhr, K. L. (2012). Contributions of Endocannabinoid Signaling to Psychiatric Disorders in Humans: Genetic and Biochemical Evidence. Neuroscience 204, 207-229. doi:10.1016/j. neuroscience.2011.11.020

Hodges, E. L., Marshall, J. P., and Ashpole, N. M. (2020). Age-Dependent Hormesis-Like Effects of the Synthetic Cannabinoid CP55940 in C57BL/6 Mice. Npj Aging Mech. Dis. 6, 7. doi:10.1038/s41514-020-0045-7

Howlett, A. C., Barth, F., Bonner, T. I., Cabral, G., Casellas, P., Devane, W. A., et al. (2002). International Union of Pharmacology. XXVII. Classification of Cannabinoid Receptors. Pharmacol. Rev. 54, 161-202. doi:10.1124/pr.54.2.161

Hutchinson, M. R., Zhang, Y., Shridhar, M., Evans, J. H., Buchanan, M. M., Zhao, T. X., et al. (2010). Evidence that Opioids May Have Toll-Like Receptor 4 and MD-2 Effects. Brain Behav. Immun. 24, 83-95. doi:10.1016/j.bbi.2009.08.004

Ibsen, M. S., Connor, M., and Glass, M. (2017). Cannabinoid CB1 and CB2 Receptor Signaling and Bias. Cannabis Cannabinoid Res. 2, 48-60. doi:10.1089/ can.2016.0037

Imamura, K., Hishikawa, N., Sawada, M., Nagatsu, T., Yoshida, M., and Hashizume, Y. (2003). Distribution of Major Histocompatibility Complex Class II-Positive Microglia and Cytokine Profile of Parkinson's Disease Brains. Acta Neuropathol. 106, 518-526. doi:10.1007/s00401-0030766-2

Javed, H., Azimullah, S., Haque, M. E., and Ojha, S. K. (2016). Cannabinoid Type 2 (CB2) Receptors Activation Protects against Oxidative Stress and Neuroinflammation Associated Dopaminergic Neurodegeneration in Rotenone Model of Parkinson's Disease. Front. Neurosci. 10, 321. doi:10. 3389/fnins.2016.00321

Jung, K. M., Astarita, G., Yasar, S., Vasilevko, V., Cribbs, D. H., Head, E., et al. (2012). An Amyloid $\beta 42$-Dependent Deficit in Anandamide Mobilization Is
Associated with Cognitive Dysfunction in Alzheimer's Disease. Neurobiol. Aging 33, 1522-1532. doi:10.1016/j.neurobiolaging.2011.03.012

Kathuria, S., Gaetani, S., Fegley, D., Valiño, F., Duranti, A., Tontini, A., et al. (2003). Modulation of Anxiety through Blockade of Anandamide Hydrolysis. Nat. Med. 9, 76-81. doi:10.1038/nm803

Kim, S. H., Smith, C. J., and Van Eldik, L. J. (2004). Importance of MAPK Pathways for Microglial Pro-inflammatory Cytokine IL-1 Beta Production. Neurobiol. Aging 25, 431-439. doi:10.1016/S0197-4580(03)00126-X

Köfalvi, A., Moreno, E., Cordomí, A., Cai, N.-S., Fernández-Dueñas, V., Ferreira, S. G., et al. (2020). Control of Glutamate Release by Complexes of Adenosine and Cannabinoid Receptors. BMC Biol. 18, 9. doi:10.1186/s12915-0200739-0

Komorowska-Müller, J. A., and Schmöle, A.-C. (2020). CB2 Receptor in Microglia: The Guardian of Self-Control. Ijms 22, 19. doi:10.3390/ijms22010019

Laprairie, R. B., Kelly, M. E., and Denovan-Wright, E. M. (2013). Cannabinoids Increase Type 1 Cannabinoid Receptor Expression in a Cell Culture Model of Striatal Neurons: Implications for Huntington's Disease. Neuropharmacology 72, 47-57. doi:10.1016/j.neuropharm.2013.04.006

Laprairie, R. B., Bagher, A. M., Rourke, J. L., Zrein, A., Cairns, E. A., Kelly, M. E. M., et al. (2019). Positive Allosteric Modulation of the Type 1 Cannabinoid Receptor Reduces the Signs and Symptoms of Huntington's Disease in the R6/2 Mouse Model. Neuropharmacology 151, 1-12. doi:10.1016/j.neuropharm. 2019.03.033

Lastres-Becker, I., Berrendero, F., Lucas, J. J., Martín-Aparicio, E., Yamamoto, A., Ramos, J. A., et al. (2002). Loss of mRNA Levels, Binding and Activation of GTP-Binding Proteins for Cannabinoid CB1 Receptors in the Basal Ganglia of a Transgenic Model of Huntington's Disease. Brain Res. 929, 236-242. doi:10. 1016/s0006-8993(01)03403-5

Li, C., Shi, J., Wang, B., Li, J., and Jia, H. (2019a). CB2 Cannabinoid Receptor Agonist Ameliorates Novel Object Recognition but Not Spatial Memory in Transgenic APP/PS1 Mice. Neurosci. Lett. 707, 134286. doi:10.1016/j.neulet. 2019.134286

Li, M., Zhang, D., Ge, X., Zhu, X., Zhou, Y., Zhang, Y., et al. (2019b). TRAF6-p38/ JNK-ATF2 Axis Promotes Microglial Inflammatory Activation. Exp. Cel Res 376, 133-148. doi:10.1016/j.yexcr.2019.02.005

López-Sendón Moreno, J. L., García Caldentey, J., Trigo Cubillo, P., Ruiz Romero, C., García Ribas, G., Alonso Arias, M. A. A., et al. (2016). A Double-Blind, Randomized, Cross-Over, Placebo-Controlled, Pilot Trial with Sativex in Huntington's Disease. J. Neurol. 263, 1390-1400. doi:10.1007/s00415-016$8145-9$

Long, J. Z., Nomura, D. K., Vann, R. E., Walentiny, D. M., Booker, L., Jin, X., et al. (2009). Dual Blockade of FAAH and MAGL Identifies Behavioral Processes Regulated by Endocannabinoid Crosstalk In Vivo. Proc. Natl. Acad. Sci. U S A. 106, 20270-20275. doi:10.1073/pnas.0909411106

Lu, H. C., and Mackie, K. (2016). An Introduction to the Endogenous Cannabinoid System. Biol. Psychiatry 79, 516-525. doi:10.1016/j.biopsych.2015.07.028

Lukiw, W. J. (2004). Gene Expression Profiling in Fetal, Aged, and Alzheimer hippocampus: A Continuum of Stress-Related Signaling. Neurochem. Res. 29, 1287-1297. doi:10.1023/b:nere.0000023615.89699.63

Lynn, A. B., and Herkenham, M. (1994). Localization of Cannabinoid Receptors and Nonsaturable High-Density Cannabinoid Binding Sites in Peripheral Tissues of the Rat: Implications for Receptor-Mediated Immune Modulation by Cannabinoids. J. Pharmacol. Exp. Ther. 268, 1612-1623.

Ma, L., Jia, J., Liu, X., Bai, F., Wang, Q., and Xiong, L. (2015). Activation of Murine Microglial N9 Cells Is Attenuated through Cannabinoid Receptor CB2 Signaling. Biochem. Biophys. Res. Commun. 458, 92-97. doi:10.1016/j.bbrc. 2015.01.073

Maccarrone, M., Gubellini, P., Bari, M., Picconi, B., Battista, N., Centonze, D., et al. (2003). Levodopa Treatment Reverses Endocannabinoid System Abnormalities in Experimental Parkinsonism. J. Neurochem. 85, 1018-1025. doi:10.1046/j. 1471-4159.2003.01759.x

Mailleux, P., and Vanderhaeghen, J. J. (1992). Age-related Loss of Cannabinoid Receptor Binding Sites and mRNA in the Rat Striatum. Neurosci. Lett. 147, 179-181. doi:10.1016/0304-3940(92)90589-y

Maresz, K., Carrier, E. J., Ponomarev, E. D., Hillard, C. J., and Dittel, B. N. (2005). Modulation of the Cannabinoid CB2 Receptor in Microglial Cells in Response to Inflammatory Stimuli. J. Neurochem. 95, 437-445. doi:10.1111/j.1471-4159. 2005.03380.x 
Marsicano, G., and Lutz, B. (1999). Expression of the Cannabinoid Receptor CB1 in Distinct Neuronal Subpopulations in the Adult Mouse Forebrain. Eur. J. Neurosci. 11, 4213-4225. doi:10.1046/j.1460-9568.1999.00847.x

Martín-Moreno, A. M., Brera, B., Spuch, C., Carro, E., García-García, L., Delgado, M., et al. (2012). Prolonged Oral Cannabinoid Administration Prevents Neuroinflammation, Lowers $\beta$-amyloid Levels and Improves Cognitive Performance in Tg APP 2576 Mice. J. Neuroinflammation 9, 8. doi:10.1186/ 1742-2094-9-8

Matias, I., Petrosino, S., Racioppi, A., Capasso, R., Izzo, A. A., and Di Marzo, V. (2008). Dysregulation of Peripheral Endocannabinoid Levels in Hyperglycemia and Obesity: Effect of High Fat Diets. Mol. Cel Endocrinol 286, S66-S78. doi:10. 1016/j.mce.2008.01.026

McCoy, K. L., Matveyeva, M., Carlisle, S. J., and Cabral, G. A. (1999). Cannabinoid Inhibition of the Processing of Intact Lysozyme by Macrophages: Evidence for CB2 Receptor Participation. J. Pharmacol. Exp. Ther. 289, 1620-1625.

McGeer, P. L., Itagaki, S., Boyes, B. E., and McGeer, E. G. (1988). Reactive Microglia Are Positive for HLA-DR in the Substantia Nigra of Parkinson's and Alzheimer's Disease Brains. Neurology 38, 1285-1291. doi:10.1212/wnl.38.8. 1285

McGuire, S. O., Ling, Z. D., Lipton, J. W., Sortwell, C. E., Collier, T. J., and Carvey, P. M. (2001). Tumor Necrosis Factor Alpha Is Toxic to Embryonic Mesencephalic Dopamine Neurons. Exp. Neurol. 169, 219-230. doi:10.1006/ exnr.2001.7688

Mecha, M., Feliú, A., Carrillo-Salinas, F. J., Rueda-Zubiaurre, A., Ortega-Gutiérrez, S., de Sola, R. G., et al. (2015). Endocannabinoids Drive the Acquisition of an Alternative Phenotype in Microglia. Brain Behav. Immun. 49, 233-245. doi:10. 1016/j.bbi.2015.06.002

Mechoulam, R., Ben-Shabat, S., Hanus, L., Ligumsky, M., Kaminski, N. E., Schatz, A. R., et al. (1995). Identification of an Endogenous 2-monoglyceride, Present in Canine Gut, that Binds to Cannabinoid Receptors. Biochem. Pharmacol. 50, 83-90. doi:10.1016/0006-2952(95)00109-d

Meng, A., Zhang, X., and Shi, Y. (2014). Role of P38 MAPK and STAT3 in Lipopolysaccharide-Stimulated Mouse Alveolar Macrophages. Exp. Ther. Med. 8, 1772-1776. doi:10.3892/etm.2014.2023

Meng, Q., Lin, M. S., and Tzeng, I. S. (2020). Relationship between Exercise and Alzheimer's Disease: A Narrative Literature Review. Front. Neurosci. 14, 131. doi:10.3389/fnins.2020.00131

Motwani, M. P., Bennett, F., Norris, P. C., Maini, A. A., George, M. J., Newson, J., et al. (2018). Potent Anti-Inflammatory and Pro-Resolving Effects of Anabasum in a Human Model of Self-Resolving Acute Inflammation. Clin. Pharmacol. Ther. 104, 675-686. doi:10.1002/cpt.980

Mounsey, R. B., Mustafa, S., Robinson, L., Ross, R. A., Riedel, G., Pertwee, R. G., et al. (2015). Increasing Levels of the Endocannabinoid 2-AG Is Neuroprotective in the 1-Methyl-4-Phenyl-1,2,3,6-Tetrahydropyridine Mouse Model of Parkinson's Disease. Exp. Neurol. 273, 36-44. doi:10.1016/j. expneurol.2015.07.024

Mulder, J., Zilberter, M., Pasquaré, S. J., Alpár, A., Schulte, G., Ferreira, S. G., et al. (2011). Molecular Reorganization of Endocannabinoid Signalling in Alzheimer's Disease. Brain 134, 1041-1060. doi:10.1093/brain/awr046

Munro, S., Thomas, K. L., and Abu-Shaar, M. (1993). Molecular Characterization of a Peripheral Receptor for Cannabinoids. Nature 365, 61-65. doi:10.1038/ $365061 \mathrm{a} 0$

Murphy, M. P., and LeVine, H. (2010). Alzheimer's Disease and the Amyloid- $\beta$ Peptide. J. Alzheimers Dis. 19, 311-323. doi:10.3233/JAD-2010-1221

Navarrete, F., García-Gutiérrez, M. S., Aracil-Fernández, A., Lanciego, J. L., and Manzanares, J. (2018). Cannabinoid CB1 and CB2 Receptors, and Monoacylglycerol Lipase Gene Expression Alterations in the Basal Ganglia of Patients with Parkinson's Disease. Neurotherapeutics 15, 459-469. doi:10. 1007/s13311-018-0603-x

Navarro, G., Morales, P., Rodríguez-Cueto, C., Fernández-Ruiz, J., Jagerovic, N., and Franco, R. (2016). Targeting Cannabinoid CB2 Receptors in the Central Nervous System. Medicinal Chemistry Approaches with Focus on Neurodegenerative Disorders. Front. Neurosci. 10, 406. doi:10.3389/fnins. 2016.00406

Navarro, G., Borroto-Escuela, D., Angelats, E., Etayo, Í., Reyes-Resina, I., Pulido-Salgado, M., et al. (2018). Receptor-Heteromer Mediated Regulation of Endocannabinoid Signaling in Activated Microglia. Role of CB1 and CB2 Receptors and Relevance for Alzheimer's Disease and
Levodopa-Induced Dyskinesia. Brain Behav. Immun. 67, 139-151. doi:10. 1016/j.bbi.2017.08.015

Neumann, H., Schweigreiter, R., Yamashita, T., Rosenkranz, K., Wekerle, H., and Barde, Y. A. (2002). Tumor Necrosis Factor Inhibits Neurite Outgrowth and Branching of Hippocampal Neurons by a Rho-Dependent Mechanism. J. Neurosci. 22, 854-862. doi:10.1523/JNEUROSCI.22-03-00854.2002

Nimmerjahn, A., Kirchhoff, F., and Helmchen, F. (2005). Resting Microglial Cells Are Highly Dynamic Surveillants of Brain Parenchyma In Vivo. Science 308, 1314-1318. doi:10.1126/science.1110647

Njie, E. G., Boelen, E., Stassen, F. R., Steinbusch, H. W., Borchelt, D. R., and Streit, W. J. (2012). Ex Vivo cultures of Microglia from Young and Aged Rodent Brain Reveal Age-Related Changes in Microglial Function. Neurobiol. Aging 33, 195. doi:10.1016/j.neurobiolaging.2010.05.008

Norden, D. M., and Godbout, J. P. (2013). Review: Microglia of the Aged Brain: Primed to Be Activated and Resistant to Regulation. Neuropathol. Appl. Neurobiol. 39, 19-34. doi:10.1111/j.1365-2990.2012.01306.x

Nordengen, K., Kirsebom, B. E., Henjum, K., Selnes, P., Gísladóttir, B., Wettergreen, M., et al. (2019). Glial Activation and Inflammation along the Alzheimer's Disease Continuum. J. Neuroinflammation 16, 46-13. doi:10.1186/ s12974-019-1399-2

Núñez, E., Benito, C., Pazos, M. R., Barbachano, A., Fajardo, O., González, S., et al. (2004). Cannabinoid CB2 Receptors Are Expressed by Perivascular Microglial Cells in the Human Brain: An Immunohistochemical Study. Synapse 53, 208-213. doi:10.1002/syn.20050

Ojha, S., Javed, H., Azimullah, S., and Haque, M. E. (2016). $\beta$-Caryophyllene, a Phytocannabinoid Attenuates Oxidative Stress, Neuroinflammation, Glial Activation, and Salvages Dopaminergic Neurons in a Rat Model of Parkinson Disease. Mol. Cel Biochem 418, 59-70. doi:10.1007/s11010-0162733-y

Ouchi, Y., Yoshikawa, E., Sekine, Y., Futatsubashi, M., Kanno, T., Ogusu, T., et al. (2005). Microglial Activation and Dopamine Terminal Loss in Early Parkinson's Disease. Ann. Neurol. 57, 168-175. doi:10.1002/ana.20338

Pacher, P., Bátkai, S., and Kunos, G. (2006). The Endocannabinoid System as an Emerging Target of Pharmacotherapy. Pharmacol. Rev. 58, 389-462. doi:10. $1124 /$ pr.58.3.2

Pagotto, U., Marsicano, G., Cota, D., Lutz, B., and Pasquali, R. (2006). The Emerging Role of the Endocannabinoid System in Endocrine Regulation and Energy Balance. Endocr. Rev. 27, 73-100. doi:10.1210/er.2005-0009

Palazuelos, J., Aguado, T., Pazos, M. R., Julien, B., Carrasco, C., Resel, E., et al. (2009). Microglial CB2 Cannabinoid Receptors Are Neuroprotective in Huntington's Disease Excitotoxicity. Brain 132, 3152-3164. doi:10.1093/ brain/awp239

Pascual, A. C., Gaveglio, V. L., Giusto, N. M., and Pasquaré, S. J. (2014). Cannabinoid Receptor-Dependent Metabolism of 2-Arachidonoylglycerol during Aging. Exp. Gerontol. 55, 134-142. doi:10.1016/j.exger.2014.04.008

Pavese, N., Gerhard, A., Tai, Y. F., Ho, A. K., Turkheimer, F., Barker, R. A., et al. (2006). Microglial Activation Correlates with Severity in Huntington Disease: A Clinical and PET Study. Neurology 66, 1638-1643. doi:10.1212/01.wnl. 0000222734.56412 .17

Perry, V. H., Nicoll, J. A., and Holmes, C. (2010). Microglia in Neurodegenerative Disease. Nat. Rev. Neurol. 6, 193-201. doi:10.1038/nrneurol.2010.17

Price, D. A., Martinez, A. A., Seillier, A., Koek, W., Acosta, Y., Fernandez, E., et al. (2009). WIN55,212-2, a Cannabinoid Receptor Agonist, Protects against Nigrostriatal Cell Loss in the 1-Methyl-4-Phenyl-1,2,3,6-Tetrahydropyridine Mouse Model of Parkinson's Disease. Eur. J. Neurosci. 29, 2177-2186. doi:10. $1111 / j .1460-9568.2009 .06764 . x$

Quarta, C., and Cota, D. (2020). Anti-Obesity Therapy with Peripheral CB1 Blockers: From Promise to Safe(?) Practice. Int. J. Obes. (Lond) 44, 2179-2193. doi:10.1038/s41366-020-0577-8

Raj, D., Yin, Z., Breur, M., Doorduin, J., Holtman, I. R., Olah, M., et al. (2017). Increased White Matter Inflammation in Aging- and Alzheimer's Disease Brain. Front. Mol. Neurosci. 10, 206. doi:10.3389/fnmol.2017.00206

Reusch, N., Ravichandran, K. A., Olabiyi, B. F., Komorowska-Müller, J. A., Hansen, J. N., Ulas, T., et al. (2021). Cannabinoid Receptor 2 Is Necessary to Induce TollLike Receptor-Mediated Microglial Activation. Glia 70 (1), 71-88. doi:10.1002/ glia. 24089

Richwine, A. F., Godbout, J. P., Berg, B. M., Chen, J., Escobar, J., Millard, D. K., et al. (2005). Improved Psychomotor Performance in Aged Mice Fed Diet High in 
Antioxidants Is Associated with Reduced Ex Vivo Brain Interleukin-6 Production. Brain Behav. Immun. 19, 512-520. doi:10.1016/j.bbi.2004.12.005 Rojo-Bustamante, E., Abellanas, M. A., Clavero, P., Thiolat, M. L., Li, Q., Luquin, M. R., et al. (2018). The Expression of Cannabinoid Type 1 Receptor and 2Arachidonoyl Glycerol Synthesizing/Degrading Enzymes Is Altered in Basal Ganglia during the Active Phase of Levodopa-Induced Dyskinesia. Neurobiol. Dis. 118, 64-75. doi:10.1016/j.nbd.2018.06.019

Romero, J., Berrendero, F., Garcia-Gil, L., de la Cruz, P., Ramos, J. A., and Fernández-Ruiz, J. J. (1998). Loss of Cannabinoid Receptor Binding and Messenger RNA Levels and Cannabinoid Agonist-Stimulated [35S]guanylyl5'O-(thio)-Triphosphate Binding in the Basal Ganglia of Aged Rats. Neuroscience 84, 1075-1083. doi:10.1016/S0306-4522(97)00552-6

Romero-Sandoval, E. A., Horvath, R., Landry, R. P., and DeLeo, J. A. (2009). Cannabinoid Receptor Type 2 Activation Induces a Microglial AntiInflammatory Phenotype and Reduces Migration via MKP Induction and ERK Dephosphorylation. Mol. Pain 5, 25. doi:10.1186/1744-8069-5-25

Sagredo, O., González, S., Aroyo, I., Pazos, M. R., Benito, C., Lastres-Becker, I., et al. (2009). Cannabinoid CB2 Receptor Agonists Protect the Striatum against Malonate Toxicity: Relevance for Huntington's Disease. Glia 57, 1154-1167. doi:10.1002/glia.20838

Saito, V. M., Rezende, R. M., and Teixeira, A. L. (2012). Cannabinoid Modulation of Neuroinflammatory Disorders. Curr. Neuropharmacol 10, 159-166. doi:10. 2174/157015912800604515

Sapp, E., Kegel, K. B., Aronin, N., Hashikawa, T., Uchiyama, Y., Tohyama, K., et al. (2001). Early and Progressive Accumulation of Reactive Microglia in the Huntington Disease Brain. J. Neuropathol. Exp. Neurol. 60, 161-172. doi:10. 1093/jnen/60.2.161

Saroz, Y., Kho, D. T., Glass, M., Graham, E. S., and Grimsey, N. L. (2019). Cannabinoid Receptor 2 (CB2) Signals via G-Alpha-S and Induces IL-6 and IL10 Cytokine Secretion in Human Primary Leukocytes. ACS Pharmacol. Transl Sci. 2, 414-428. doi:10.1021/acsptsci.9b00049

Schafer, D. P., Lehrman, E. K., Kautzman, A. G., Koyama, R., Mardinly, A. R., Yamasaki, R., et al. (2012). Microglia Sculpt Postnatal Neural Circuits in an Activity and Complement-Dependent Manner. Neuron 74, 691-705. doi:10. 1016/j.neuron.2012.03.026

Schatz, A. R., Lee, M., Condie, R. B., Pulaski, J. T., and Kaminski, N. E. (1997). Cannabinoid Receptors CB1 and CB2: a Characterization of Expression and Adenylate Cyclase Modulation within the Immune System. Toxicol. Appl. Pharmacol. 142, 278-287. doi:10.1006/taap.1996.8034

Selkoe, D. J., and Hardy, J. (2016). The Amyloid Hypothesis of Alzheimer's Disease at 25 years. EMBO Mol. Med. 8, 595-608. doi:10.15252/emmm.201606210

Sierra, A., Gottfried-Blackmore, A. C., McEwen, B. S., and Bulloch, K. (2007). Microglia Derived from Aging Mice Exhibit an Altered Inflammatory Profile. Glia 55, 412-424. doi:10.1002/glia.20468

Simonds, W. F., Goldsmith, P. K., Codina, J., Unson, C. G., and Spiegel, A. M. (1989). Gi2 Mediates Alpha 2-adrenergic Inhibition of Adenylyl Cyclase in Platelet Membranes: In Situ Identification with G Alpha C-Terminal Antibodies. Proc. Natl. Acad. Sci. U S A. 86, 7809-7813. doi:10.1073/pnas. 86.20.7809

Solas, M., Francis, P. T., Franco, R., and Ramirez, M. J. (2013). CB2 Receptor and Amyloid Pathology in Frontal Cortex of Alzheimer's Disease Patients. Neurobiol. Aging 34, 805-808. doi:10.1016/j.neurobiolaging.2012.06.005

Sorge, R. E., LaCroix-Fralish, M. L., Tuttle, A. H., Sotocinal, S. G., Austin, J. S., Ritchie, J., et al. (2011). Spinal Cord Toll-Like Receptor 4 Mediates Inflammatory and Neuropathic Hypersensitivity in Male but Not Female Mice. J. Neurosci. 31, 15450-15454. doi:10.1523/JNEUROSCI.3859-11.2011

Sorge, R. E., Mapplebeck, J. C., Rosen, S., Beggs, S., Taves, S., Alexander, J. K., et al. (2015). Different Immune Cells Mediate Mechanical Pain Hypersensitivity in Male and Female Mice. Nat. Neurosci. 18, 1081-1083. doi:10.1038/nn.4053

Spangenberg, E. E., Lee, R. J., Najafi, A. R., Rice, R. A., Elmore, M. R., Blurton-Jones, M., et al. (2016). Eliminating Microglia in Alzheimer's Mice Prevents Neuronal Loss without Modulating Amyloid- $\beta$ Pathology. Brain 139, 1265-1281. doi:10. 1093/brain/aww016

Spangenberg, E., Severson, P. L., Hohsfield, L. A., Crapser, J., Zhang, J., Burton, E. A., et al. (2019). Sustained Microglial Depletion with CSF1R Inhibitor Impairs Parenchymal Plaque Development in an Alzheimer's Disease Model. Nat. Commun. 10, 3758. doi:10.1038/s41467-019-11674-Z
Stella, N., Schweitzer, P., and Piomelli, D. (1997). A Second Endogenous Cannabinoid that Modulates Long-Term Potentiation. Nature 388, 773-778. doi: $10.1038 / 42015$

Stella, N. (2009). Endocannabinoid Signaling in Microglial Cells. Neuropharmacology 56, 244-253. doi:10.1016/j.neuropharm.2008.07.037

Stella, N. (2010). Cannabinoid and Cannabinoid-Like Receptors in Microglia, Astrocytes, and Astrocytomas. Glia 58, 1017-1030. doi:10.1002/glia.20983

Stevens, B., Allen, N. J., Vazquez, L. E., Howell, G. R., Christopherson, K. S., Nouri, N., et al. (2007). The Classical Complement cascade Mediates CNS Synapse Elimination. Cell 131, 1164-1178. doi:10.1016/j.cell.2007.10.036

Streit, W. J., Sammons, N. W., Kuhns, A. J., and Sparks, D. L. (2004). Dystrophic Microglia in the Aging Human Brain. Glia 45, 208-212. doi:10.1002/glia.10319

Sugiura, T., Kondo, S., Sukagawa, A., Nakane, S., Shinoda, A., Itoh, K., et al. (1995). 2-Arachidonoylglycerol: A Possible Endogenous Cannabinoid Receptor Ligand in Brain. Biochem. Biophys. Res. Commun. 215, 89-97. doi:10.1006/bbrc.1995. 2437

Sugiura, T., Kondo, S., Kishimoto, S., Miyashita, T., Nakane, S., Kodaka, T., et al. (2000). Evidence that 2-arachidonoylglycerol but Not N-Palmitoylethanolamine or Anandamide Is the Physiological Ligand for the Cannabinoid CB2 Receptor. Comparison of the Agonistic Activities of Various Cannabinoid Receptor Ligands in HL-60 Cells. J. Biol. Chem. 275, 605-612. doi:10.1074/jbc.275.1.605

Tai, Y. F., Pavese, N., Gerhard, A., Tabrizi, S. J., Barker, R. A., Brooks, D. J., et al. (2007a). Imaging Microglial Activation in Huntington's Disease. Brain Res. Bull. 72, 148-151. doi:10.1016/j.brainresbull.2006.10.029

Tai, Y. F., Pavese, N., Gerhard, A., Tabrizi, S. J., Barker, R. A., Brooks, D. J., et al. (2007b). Microglial Activation in Presymptomatic Huntington's Disease Gene Carriers. Brain 130, 1759-1766. doi:10.1093/brain/awm044

Tanaka, M., Sackett, S., and Zhang, Y. (2020). Endocannabinoid Modulation of Microglial Phenotypes in Neuropathology. Front. Neurol. 11, 87. doi:10.3389/ fneur.2020.00087

Tao, Y., Li, L., Jiang, B., Feng, Z., Yang, L., Tang, J., et al. (2016). Cannabinoid Receptor-2 Stimulation Suppresses Neuroinflammation by Regulating Microglial M1/M2 Polarization through the cAMP/PKA Pathway in an Experimental GMH Rat Model. Brain Behav. Immun. 58, 118-129. doi:10. 1016/j.bbi.2016.05.020

Tolón, R. M., Núñez, E., Pazos, M. R., Benito, C., Castillo, A. I., Martínez-Orgado, J. A., et al. (2009). The Activation of Cannabinoid CB2 Receptors Stimulates In Situ and In Vitro Beta-Amyloid Removal by Human Macrophages. Brain Res. 1283, 148-154. doi:10.1016/j.brainres.2009.05.098

Varin, A., and Gordon, S. (2009). Alternative Activation of Macrophages: Immune Function and Cellular Biology. Immunobiology 214, 630-641. doi:10.1016/j. imbio.2008.11.009

Villeda, S. A., Luo, J., Mosher, K. I., Zou, B., Britschgi, M., Bieri, G., et al. (2011). The Ageing Systemic Milieu Negatively Regulates Neurogenesis and Cognitive Function. Nature 477, 90-94. doi:10.1038/nature10357

Waetzig, V., Czeloth, K., Hidding, U., Mielke, K., Kanzow, M., Brecht, S., et al. (2005). c-Jun N-Terminal Kinases (JNKs) Mediate Pro-Inflammatory Actions of Microglia. Glia 50, 235-246. doi:10.1002/glia.20173

Wang, W. Y., Tan, M. S., Yu, J. T., and Tan, L. (2015). Role of Pro-Inflammatory Cytokines Released from Microglia in Alzheimer's Disease. Ann. Transl Med. 3, 136. doi:10.3978/j.issn.2305-5839.2015.03.49

Weaver, J. D., Huang, M. H., Albert, M., Harris, T., Rowe, J. W., and Seeman, T. E. (2002). Interleukin-6 and Risk of Cognitive Decline: MacArthur Studies of Successful Aging. Neurology 59, 371-378. doi:10.1212/wnl.59.3.371

Wynne, A. M., Henry, C. J., Huang, Y., Cleland, A., and Godbout, J. P. (2010). Protracted Downregulation of CX3CR1 on Microglia of Aged Mice after Lipopolysaccharide Challenge. Brain Behav. Immun. 24, 1190-1201. doi:10. 1016/j.bbi.2010.05.011

Xing, G., Carlton, J., Jiang, X., Wen, J., Jia, M., and Li, H. (2014). Differential Expression of Brain Cannabinoid Receptors between Repeatedly Stressed Males and Females May Play a Role in Age and Gender-Related Difference in Traumatic Brain Injury: Implications from Animal Studies. Front. Neurol. 5, 161. doi:10.3389/fneur.2014.00161

Ye, S. M., and Johnson, R. W. (1999). Increased Interleukin-6 Expression by Microglia from Brain of Aged Mice. J. Neuroimmunol 93, 139-148. doi:10.1016/ s0165-5728(98)00217-3 
Ye, S. M., and Johnson, R. W. (2001). An Age-Related Decline in Interleukin-10 May Contribute to the Increased Expression of Interleukin-6 in Brain of Aged Mice. Neuroimmunomodulation 9, 183-192. doi:10.1159/000049025

Zahn, J. M., Poosala, S., Owen, A. B., Ingram, D. K., Lustig, A., Carter, A., et al. (2007). AGEMAP: A Gene Expression Database for Aging in Mice. Plos Genet. 3, e201. doi:10.1371/journal.pgen.0030201

Zhang, B., Gaiteri, C., Bodea, L. G., Wang, Z., McElwee, J., Podtelezhnikov, A. A., et al. (2013). Integrated Systems Approach Identifies Genetic Nodes and Networks in Late-Onset Alzheimer's Disease. Cell 153, 707-720. doi:10.1016/j.cell.2013.03.030

Conflict of Interest: The authors declare that the research was conducted in the absence of any commercial or financial relationships that could be construed as a potential conflict of interest.
Publisher's Note: All claims expressed in this article are solely those of the authors and do not necessarily represent those of their affiliated organizations, or those of the publisher, the editors and the reviewers. Any product that may be evaluated in this article, or claim that may be made by its manufacturer, is not guaranteed or endorsed by the publisher.

Copyright (c) 2022 Young and Denovan-Wright. This is an open-access article distributed under the terms of the Creative Commons Attribution License (CC $B Y)$. The use, distribution or reproduction in other forums is permitted, provided the original author(s) and the copyright owner(s) are credited and that the original publication in this journal is cited, in accordance with accepted academic practice. No use, distribution or reproduction is permitted which does not comply with these terms. 